\title{
Exploring accessibility and social inclusion for children with hearing impairments in residential camps through the occupational therapy lens
}

\author{
Tiffany Coles \\ University of St. Augustine for Health Sciences \\ DOI: https://doi.org/10.46409/sr.OUCQ5142
}

Follow this and additional works at: https://soar.usa.edu/capstones

Part of the Accessibility Commons, American Sign Language Commons, Behavior and Behavior Mechanisms Commons, Development Studies Commons, Disability Studies Commons, Educational Leadership Commons, Interpersonal and Small Group Communication Commons, Leadership Studies Commons, Occupational Therapy Commons, Online and Distance Education Commons, Other Education Commons, Other Mental and Social Health Commons, Other Rehabilitation and Therapy Commons, Outdoor Education Commons, and the Recreational Therapy Commons

\section{Recommended Citation}

Coles, T. (2020). Exploring accessibility and social inclusion for children with hearing impairments in residential camps through the occupational therapy lens. [Doctoral project, University of St Augustine for Health Sciences]. SOAR @ USA: Student Capstone Projects Collection. https://doi.org/10.46409/ sr.OUCQ5142

This Capstone is brought to you for free and open access by the Student Research at SOAR @ USA. It has been accepted for inclusion in Student Capstone Projects by an authorized administrator of SOAR @ USA. For more information, please contact soar@usa.edu, erobinson@usa.edu. 


\section{EXPLORING ACCESSIBILITY AND SOCIAL INCLUSION FOR CHILDREN WITH HEARING IMPAIRMENTS IN RESIDENTIAL CAMPS THROUGH THE OCCUPATIONAL THERAPY LENS}

Tiffany L. Coles

Department of Occupational Therapy, University of St. Augustine for Health Sciences

A Capstone Presented in Partial Fulfillment

of the Requirement for the Degree

DOCTOR OF OCCUPATIONAL THERAPY

University of St. Augustine for Health Sciences

December 2020 


\section{EXPLORING ACCESSIBILITY AND SOCIAL INCLUSION FOR CHILDREN WITH HEARING IMPAIRMENTS IN RESIDENTIAL CAMPS THROUGH THE OCCUPATIONAL THERAPY LENS}

\section{Tiffany L. Coles}

Department of Occupational Therapy, University of St. Augustine for Health Sciences has been approved

December 2020

APPROVAL:

Susan MacDermott, OTD, OTR/L, Doctoral Coordinator

Becki Cohill, OTD, OTR/L, Doctoral Coordinator

Erin Schwier, EdD, OTD, OTR/L, Program Director

ACCEPTED AND SIGNED:

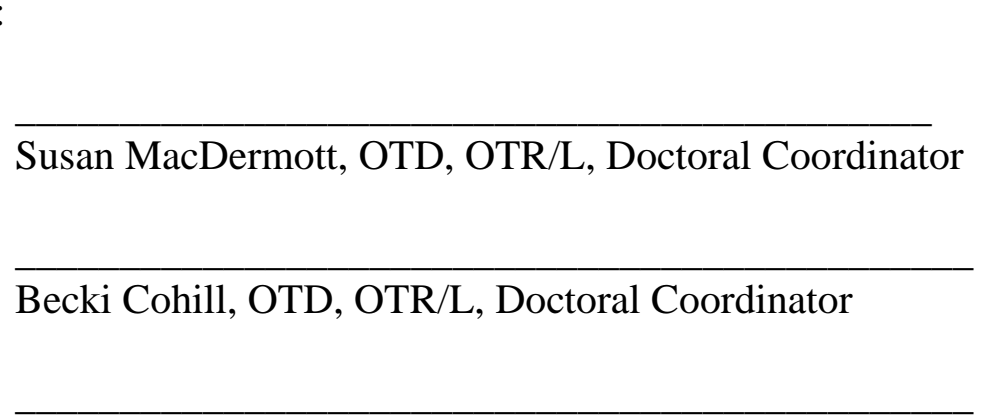

Erin Schwier, EdD, OTD, OTR/L, Program Director 


\section{Table of Contents}

Chapter 1: Introduction

Background

Statement of the Problem

Purpose Statement

Rationale for Proposed Project

Significance of the Proposed Project

Objectives

Definition of terms

Assumptions, Limitations, and Delimitations

The Role of Social Inclusion in Residential Camps

The Role of Occupational Therapy in Residential Camps

Impact of Camp Counselors on Occupational and Social Development

Parents as a Perceived Barrier

Process and Methods

Timeline 
Parents Influence on Counselors

Inclusion in Camp Activities

Analysis

Motivation to Become a Counselor

Campers Model Behaviors off Counselors

Accommodations Needed within the Camp

Further Counselor Training is Needed

Chapter 5: Discussion and Conclusion

OT implications

Envisioned Next Steps

Conclusion

References

Appendix A- IRB Approval

Appendix B- Email and Social Media Script

Appendix C- Survey Consent Form

Appendix D- Survey Questions 
$\begin{array}{ll}\text { ASL Dictionary } & 66\end{array}$

$\begin{array}{ll}\text { Additional Resources } & 66\end{array}$

$\begin{array}{ll}\text { Appendix F- Poster Presentation } & 67\end{array}$

Copyright (C) Tiffany L. Coles, 2020 all rights reserved 


\section{Exploring Accessibility and Social Inclusion for Children with Hearing Impairments in Residential Camps Through the Occupational Therapy Lens}

\section{Chapter 1: Introduction}

The purpose of this proposal is to outline the vision for this capstone project of enhancing social acceptance and inclusion of hearing-impaired children in residential camp settings.

\section{Background}

The World Health Organization (WHO, n.d.) estimates that disabling hearing loss affects approximately 34 million children worldwide. Within the United States, 3 million children have hearing loss (Center for Hearing and Communication [CHC], n.d.). The cause of hearing loss and deafness can be classified as either congenital or acquired. Congenital hearing loss arises from genetic factors, or complications during pregnancy and childbirth, and is present or acquired soon after birth (WHO, n.d.). Acquired hearing loss can be developed at any age from illness, infection, injury, ageing or overexposure to loud noises (WHO, n.d.).

Hearing-impairment and deafness may impact a variety of physical and mental aspects throughout the child's life. Implications of hearing loss can be functional, social-emotional, or economic (Tsakiropoulou et al., 2007). Functional implications of hearing loss may impair a child's ability to communicate within his or her community. Social-emotional impacts may include feeling excluded or isolated, and frustrated. Economic implications are a much higher rate of unemployment amongst adults with hearing impairments (Tsakiropoulou et al., 2007). The $\mathrm{CHC}$ reported that $90 \%$ of deaf children are born to hearing parents, and that $72 \%$ of families do not sign with their deaf child. The lack of consistent and effective social interaction may lead to feelings of isolation, decreased self-esteem and social skills that can make interacting with hearing peers difficult. An article written by Devine et al. states that youth with 
hearing impairments may have poorer social competence and perceptions of social acceptance in comparison to their peers without hearing impairments (2015).

Children are frequently encouraged to engage in various play, leisure, and social participation activities to enhance the development of life skills, independence, and social skills (iD Tech, n.d.). A common leisure and social participation activity for children aged 6 to 18years-old is to attend residential camp. The American Camp Association (ACA) reports that more than 14 million children and adults attend camp in the U.S each year (2017). Residential camps provide children a structured opportunity to engage in leisure activities while learning to become independent and self-confident when socializing and making new friends (iD Tech, n.d.). According to Bialeschki et al. attending camp can be a fun and engaging environment to help accelerate growth in key developmental outcomes. Such as positive identity, social skills, physical skills, positive values, and spirituality (2007).

The ACA reports that $44 \%$ of camps offer specialized programs for individuals with disabilities (2017). Specialized programs that host campers with similar disabilities are labeled as 'disability-specific' camps, whereas camps that host children that are both disabled and nondisabled are considered inclusive (Knapp et. al., 2015). Disability-specific camps were created to enhance the feeling of community and to allow children with disabilities to connect with peers that share similar life experiences (Knapp et. al., 2015). Campers that have attended disabilityspecific camps expressed feelings of acceptance, understanding, and a connection to other campers (Knapp et. al., 2015). In comparison, children with disabilities who attended inclusive camps, had mixed feelings about the experience. Research on inclusive camps suggest that children with disabilities may continue to experience exclusion from physical activity and leadership opportunities, social isolation, and stigma (D'Eloia \& Price, 2018). There is a gap in 
the evidence that suggests that attending a disability specific camp instead of an inclusive camp has more beneficial outcomes in terms of social acceptance and inclusion (Bialeschki et. al., 2007). An article written by Bialeschki et. al., about the experiences of children with disabilities attending a disability-specific camp states that "although youth with disabilities gained independence [within the disability-specific camp setting]; youth without disabilities also improved their social interactions and gained a greater appreciation of people who were different than themselves [within the inclusive camp setting]" (2007. p. 775). Thus, contributing to the concept that inclusive camps may offer positive benefits of social inclusion and acceptance for both children with and without disabilities. While the research is based on children with general disabilities, the information can also be applied to children with hearing impairments.

When a disability such as hearing loss affects the ability to participate in daily occupations, occupational therapists can assist in finding solutions to address and reduce the burden of impaired hearing. Occupational therapy addresses everyday occupations that bring meaning to one's life (American Occupational Therapy Association [AOTA], 2017). The term "occupation" is defined in the Occupational Therapy Practice Framework (AOTA, 2017) as various life activities in which individuals, groups, or populations engage. Occupations can be classified as play, leisure, and social participation within the practice framework (AOTA, 2017). Occupational therapists have the skills and training necessary to contribute inclusionary techniques within residential camp settings.

Residential camp environments are conducive to helping children develop social and life skills due to the staff participation. Typical camp staff roles include recreation staff, camp counselors, dietary, and nursing (Moderow \& Tollefson, 2018). Staff that are less commonly found in camps include physical and occupational therapists. An occupational therapist's role 
within the camp can vary from aiding counselors and campers with wheelchairs, medical equipment, transfers, feeding adaptations, and following precautions during self-care activities (Moderow \& Tollefson, 2018). Occupational therapists may also help camp staff adapt activities within the camp for children with various abilities.

An occupational therapist can help to promote understanding of the relationship between social inclusion, occupational engagement and health and well-being; as well as to educate the public on inclusionary resources and collaborate in research to promote social inclusion (Canadian Association of Occupational Therapy, n.d.). Riley et al. (2017) found that the desired results of inclusive experiences for children and their families included a sense of belonging and membership, positive social relationships and friendships, and development and learning to reach their full potential (Riley et al., 2017). Attending residential camps can help to form socially inclusive bonds and friendships with typical hearing children. Using occupational therapy’s inclusionary practices within the camp environment can help the child to further develop coping and other life skills to be able to socialize and function independently within the society.

Within the residential camp setting, children are encouraged to become self-reliant away from their caregivers while participating in their activities of daily living; as well as explore new occupations such as learning new camp songs, swimming, hiking, crafting, archery and other activities provided by the camp. The introduction of the new occupations, in a new environment may present challenges for children with hearing impairments (Moderow \& Tollefson, 2018). Primary occupational goals of camp include the "promotion of friendship development, social connection to peers with hearing impairments, self-advocacy skills, and verbal and nonverbal communication skills" (Devine et al., 2015. p. 298). By attending camp, the child has an opportunity to empower themselves by learning to self-advocate when they are unable to hear or 
need adapted services (Devine et al., 2015). With the help of an occupational therapist, camp counselors can be taught strategies to encourage social skills, communication, and inclusion within the camp environment.

The Person-Environment-Occupation-Performance (PEOP) model emphasizes the occupational performance shaped by interactions between the person, environment, and occupation (Baum et. al., 2015). The use of this model will help to assess the environment to identify factors that may restrict performance and mastery in social participation. Intervention strategies aim to improve occupational performance and competency, develop life-long skills, and increase the sense of health and well-being (Baum et. al., 2015). Being in an inclusive environment can create a positive reinforcement cycle based on both intrinsic and extrinsic factors (Baum et. al., 2015). Intrinsic factors may stem from the self-accomplishment of developing skills and abilities to effectively communicate and interact with peers. External motivators may stem from gaining feelings of social acceptance and camaraderie within the camp setting. A cycle of positive reinforcement could be to translate the techniques learned from camp into community engagement. Throughout the lifespan, a person will need to adapt aspects of their life to fulfill his or her required mastery. Adaptation requires that a person can confront challenges of daily living while utilizing any available resources in the process (Baum et. al., 2015). Participation in a residential camp can help to establish the PEOP connection of wellbeing and quality of life.

This capstone project will work to address the social conditions that lead to occupational injustice for hearing-impaired children in residential camp environments; through the education of camp staff and by enhancing and adapting the camp environment to meet the physical and social needs of hearing-impaired children. 


\section{Statement of the Problem}

Many families who have children with disabilities often find their recreational choices significantly limited. They are typically directed toward programs that are segregated “special” programs just for children with disabilities (Hall et al., 2013). By providing inclusive opportunities, families can choose recreational programs that are right for them and offer them the ability to be a part of a diverse, rich community (Hall et al., 2013). There are practical limitations to inclusion such as staff training, equipment, and curriculum; in addition to public awareness and shifts in mindset and beliefs (Hall et al., 2013). Developing peer relationships is a key element of youth development (Henderson, 2012). Camps should intentionally incorporate experiences, opportunities, and support to address and advance the positive development of children and youth (Henderson, 2012). The study found that campers commented that the skills they learned at camp, such as leadership, communication, organization, and decision-making were critical to being able to work with other people (Henderson, 2012). Investigation of the effects of a disability awareness program in a recreational setting affects the attitudes towards children with a disability (Papaioannou et al., 2012). The study indicates that a disability awareness program employed in a recreational setting effectively increases both general and sport-specific attitudes towards peers with disabilities (Papaioannou et al., 2012).

Residential camps are a great environment for children to experience a sense of community and belonging. However, many children with disabilities lack opportunities to connect with others who have similar life experiences (Knapp et al., 2015). Parents of children with disabilities are typically hesitant to allow their children to participate in recreational activities such as residential camping as they are concerned for their child's safety, lack of access and accommodations of the environment, and social acceptance of his or her disability from their 
peers (Schleien et al., 2014). A potential reason may be due to an uncertainty if the camp staff has the proper training work with their child's disability.

Occupational therapists have the skills necessary to help develop camp programs to be comfortable, restorative, socially inclusive and therapeutic for children and adolescents with disabilities (Moderow \& Tollefson, 2018). However, due to the lack of research addressing occupational therapists working within residential camps, further research is needed.

\section{Purpose Statement}

The focus of this capstone project is to educate camp staff on strategies to enhance accessibility and inclusion to create an inclusive residential camp environment for children that are deaf or hearing-impaired. Social inclusion can be defined as having opportunities, resources, and capabilities to fully participate in life (Pereira, 2017). As a profession, occupational therapy practitioners have the knowledge and skills to offer strategies to increase social acceptance and inclusion of hearing-impaired children with their hearing peers. Using occupation-focused skills and processes, occupational therapists are trained to advocate for and facilitate occupational outcomes that can enhance a person or group's capabilities, social inclusion, and wellbeing (Pereira, 2017). Within a residential camp setting, the focus of inclusion should target equity in valuable opportunities and activity participation, communication, and social justice of individuals with hearing impairments. The goal of inclusion can be accomplished through various techniques including policy and program development founded on the principles of social inclusion. Modifications of teaching strategies to include verbal support, problem solving, and videotaped instructions can assist with the child's needs (Canadian Association of Occupational Therapy, n.d.). 


\section{Rationale for Proposed Project}

This project is needed to provide educational information for all camps to become more inclusive for children with hearing-impairments. Residential camps should offer children with hearing-impairments proper access to participate in camp activities. This increased access can be achieved by overcoming structural, systematic, and social barriers present. Doing so will increase social acceptance and provide inclusion strategies that can be applied throughout the community and throughout the individual's lifetime. Research from Riley, et al. (2017), states all children and youth with disabilities have a fundamental right to live, learn, play, and work alongside their typical peers. Attending a residential camp is a great way for a child to gain independence, build self-confidence, and learn to form strong bonds with their peers (Riley et al., 2017).

To achieve equal rights and address the social disparity, the occupational injustices regarding residential camping for children with disabilities must be addressed. Occupational justice consists of three foundational ideas; the first is that occupational justice is only served when conditions allow people to engage in occupations in ways that are consistent with their culture and beliefs (Hocking, 2017). Secondly, occupation is contextually embedded, which means that structural factors and personal characteristics are determinants of occupation (Hocking, 2017). Lastly, engaging in occupation can improve the lives of people in vulnerable situations (Hocking, 2017). Ultimately, occupational justice helps to bridge the gap between an individual well-being and negative social conditions that restrict what he or she can do and be (Hocking, 2017).

This project aims to decrease occupational injustice by creating an environment that is the most socially inclusive for children with hearing impairments. The purpose is not to take 
away from the Deaf culture and the community they have created. It is to enhance and incorporate the culture within society to decrease the occurrence of occupational injustice within the residential camp setting. Residential camps typically offer opportunities for children to experience activities that they would not normally encounter in their daily routines in the classroom, at home, or in their community (ACA, 2017). Engagement within an inclusive camp environment will work to decrease occupational injustices by adapting limiting conditions such as lack of camp counselor training, poor communication, and unequal opportunities for social participation; to support an inclusive camp society by promoting education about social inclusion.

\section{Significance of the Proposed Project}

Research shows that when attending an inclusive camp, children with disabilities demonstrated increased independence with camp participation (Bialeschki et al., 2007). Additionally, children without disabilities also improved their social interactions and gained a greater appreciation of people who were different than themselves (Bialeschki et al., 2007). Inclusive camps provide a reprieve from perceptions of disability isolation for campers that result in gains in self-reliance and independence as well as an appreciation of their physical capabilities (Bialeschki et al., 2007). A study by Bialeschki et. al., (2007) found that campers who would be marginalized in other settings had decreased feelings of isolation, as well as increased feelings of self-esteem, familial acceptance, personal security, and social skills. The training and behaviors of the camp staff, camp philosophy, and attitudes of other children play an important role in facilitating and encouraging these developments.

The goal of the residential camp experience is to create a sense of community among campers (Devine et al., 2015). Disability-specific camps can help to set the stage for a sense of 
belonging and social acceptance as the child interacts with peers that share similar life experiences (Devine et al., 2015). In 1997, a movement was initiated to create a more inclusive environment within camps for children (Brannan et al., 1997). The movement worked to identify issues facing the camp environment, such as the camps' responsibility to serve campers with various conditions, as well as defining the role of a specialized camp within the mainstreaming movement (Brannan et al., 1997). There are four different dimensions of the impact of outdoor education experiences on socialization; peer socialization and peer perception, racial integration, impacts on disadvantaged groups, and teacher-student relationships (Crompton \& Sellar, 1981). The research found that students' self-concept is enhanced when these four dimensions are facilitated and improved (Crompton \& Sellar, 1981).

Residential camps offer a unique leisure experience that allows campers to interact with each other for an extended period of time (Devine et al., 2015). Within that period, opportunities for strong social support should be provided to potentially help improve the quality of life as well as social equity amongst the campers. By providing the most inclusive environment possible, all children should be able to have an equal bonding experience with their peers. Social acceptance is foundational for friendship development as it occurs when there is equal status among individuals, regardless of whether the individual has a disability or not (Devine et al., 2015). This project strives to find adaptations and ways to enhance residential camp environments to become more inclusive for individuals with hearing impairments. The camp setting is a prime resource for children with disabilities. It provides a unique, inclusive, and supportive context for a child to develop social skills, coping skills and other life skills that can be used outside of the camp setting to function independently within the society. 


\section{Objectives}

- Complete a needs assessment of current accessibility and social inclusion techniques for deaf and hard-of-hearing individuals within inclusive and disability-specific residential camps.

- Survey and interview camp staff to gain perspective of staff preparedness, methods of inclusion, accessible devices, and potential social and environmental limitations for deaf and hard-of-hearing individuals.

- Create an informational program/workshop for camp counselors to increase accessibility and social inclusion for deaf and hard-of-hearing individuals within camp settings.

- Promote the role of occupational therapy in providing inclusionary techniques for deaf and hard-of-hearing individuals within the inclusive and disability-specific residential camp setting.

- Participate in research activities to enhance research knowledge and skills.

\section{Definition of terms}

"Deaf" is referred to as being a part of the Deaf culture. Often referred to as the Deaf community. "deaf" with a lowercase 'd' is the commonly referred as the medical term of being unable to hear (National Association of the Deaf, 2020).

Hard-of-Hearing can denote a person with mild-to-moderate hearing loss or does not want cultural association with the Deaf community (Na, 2020).

$D H H$ is used as a culturally appropriate abbreviation for deaf and hard of hearing individuals. Occupational Justice is defined as that all individuals have an equal and inclusive opportunity to participate in everyday occupations regardless of age, ability, gender, social class, or other differences (Wilcock \& Townsend, 2009).

Copyright (C) Tiffany L. Coles, 2020 all rights reserved 
Disability Specific Camps are camps that are tailored to accommodate a specific type of disability (ex: autism, diabetes, cancer).

Inclusive Camps are camps that are adapted to be accessible to a wide variety of disabilities, so that children with and without disabilities can attend camp together.

\section{Assumptions, Limitations, and Delimitations}

This capstone project operates under the assumption that children who are deaf or hardof-hearing have the desire to attend inclusive camps. By attending an inclusive camp with a wide variety of children with varying needs, the child with hearing impairments will develop a deeper sense of cooperation and inclusion with their peers (Hall et al., 2013). There is the assumption that parents can potentially become barriers to a hearing-impaired child's participation within an inclusive camp environment due to their perceived beliefs about the camp accessibility and staff training. The assumption is that parents of deaf and hard-of hearing children choose to send their children to disability specific camps due to the fact that the camp environment and staff are tailored to meet the needs of their child (Schleien et al., 2014).

The limitations of this project include the barriers that parents can present due to their anxiety and fears that their child's needs may not be met within certain camp environments (Schleien et al., 2014). This project will also be limited due to the current global COVID-19 pandemic as social distancing and closure of local camps are in effect. This will limit the researcher's ability to observe accessibility, adaptations, and social interactions of the children within the camp setting. This project will be limited to virtual surveys and interviews.

Delimitations of this project include not limiting the survey and interview subjects by age. The focus of this project will be limited to the residential camp setting; however, the surveys will be presented to schools, deaf associations, and various disability-specific and inclusive 
camps. The surveys and interviews will be sent out to camp counselors, parents of children with hearing impairments, and to dear or hard-of-hearing children that have attended or are interested in attending a residential camp.

\section{Chapter 2: Literature Review}

A literature review was completed to gain an understanding of the existing research and debates relevant to children with hearing impairments attending a residential camp. Topics researched include Deaf and hard-of-hearing children, child development within camps, occupational impacts of living with hearing loss, and the presence of occupational therapy within residential camp settings. Four common themes were revealed. The themes include the role of social inclusion in residential camps, the role of occupational therapy in residential camps, the impact of camp counselors on occupational and social development, and the role parents play as a perceived barrier.

\section{The Role of Social Inclusion in Residential Camps}

The term inclusion means integration of children with disabilities into the activities and routines found within the home, education, and community settings (Riley et al., 2017). The 2020 article The Role of Recreation in Promoting Social Inclusion focuses on the various contexts of the concept of social inclusion by addressing how to define and measure social inclusion, leadership roles and social inclusion, structural barriers to social inclusion and the agency of the participants (Donnelly \& Coakley, 2002).

Not having proper access within residential camps may fall under the variant of occupational alienation or marginalization, as access for hearing impaired children may not be as heavily considered as it is for children with other types of disabilities. Hocking (2017) describes the term "occupational justice" as an aspect of social justice, with the idea is that occupational 
justice bridges the gap between people's well-being and social conditions that restrict what they

can do and be. Occupational injustice can be identified when there is occupational deprivation, imbalance, alienation, marginalization, and apartheid (Hocking, 2017).

Research on inclusive camps have shown mixed results that children continue to experience exclusion from physical activity and leadership opportunities despite being at an inclusive camp (D’Eloia \& Price, 2016). The article suggests that camps for children with disabilities may be the best delivery system to promote inclusion and a sense of belonging (D’Eloia \& Price, 2016). Knapp et al. (2015) examines the perceptions of social acceptance and quality of life amongst youth with disabilities who participated in weeklong residential camps with peers of similar disabilities. Research found that campers that attended camp with peers that share similar disabilities had strong qualitative outcomes between the constructs of social acceptance and quality of life (Knapp et al., 2015).

The purpose of this study is not to determine if one camp style is more efficient than the other; it is to identify aspects and practices from each type of camp that can be applied in a general matter. This in turn will allow children with hearing impairments and other types of disabilities the option to choose a camp based on interest and not just on accommodations available. Through research and projects such as this one, children with disabilities attending camps will feel comfortable, included, and be able to socialize with siblings or friends that do not have disabilities with ease.

\section{The Role of Occupational Therapy in Residential Camps}

The role of occupational therapists within residential camps is an emerging role that currently has limited research. However, it is an important role to discover, as occupational therapists have the knowledge and training of leisure exploration and participation to assess how 
the person, environment, occupation, and performance can impact the camper. Occupational therapists can also help to provide innovative approaches that focus on creating environments of substantive inclusion within a residential camp setting (Baum et al., 2015). Occupational therapists can utilize their training in grading activities and modifying environments in order to ensure full and appropriate participation in activities for people with disabilities (Markgraf, 2016). Services provided can include increased peer interaction, activity participation, opportunity for adaptive recreation, increased self-esteem, and respite for families (Markgraf, 2016). The OT may provide counselors with strategies to increase participation and social inclusion for the campers (Markgraf, 2016).

\section{Impact of Camp Counselors on Occupational and Social Development}

Within a camp setting the teacher-student relationship can be translated into the role the staff members play in the inclusive experience. The role of the staff under specific conditions and the influence of these factors on perceptions of the camp experience (Devine \& O'Brien, 2007). Findings from the study found that the role of the staff in inclusive recreation contexts is vitally important to the experience had by the participants (Devine \& O'Brien, 2007). Campers reported modeling their behaviors and inclusive practices off the camp staff (Devine \& O'Brien, 2007).

Further research by Devine explores the nature of relationships that develop in an inclusive youth camp context using the framework of social capital (Devine \& Parr, 2008). The study found that inclusive leisure contexts enable individuals with and without disabilities to engage in leisure together (Devine \& Parr, 2008). Devine \& Parr (2008) found that "inclusion is based on the premise that the least restrictive and integrated environments benefit both individuals with and without disabilities, in that all could experience the positive physical, 
cognitive, emotional and social outcomes of recreation participation" (pg. 392). Further

suggesting that the campers looked to the staff to see how they should behave, react, and respond to each other (Devine \& Parr, 2008). This highlighted the importance of the roles played by staff within the inclusive context, to facilitate face-to-face interaction and access to desired resources (e.g., shared norms and values) (Devine \& Parr, 2008). The importance of utilizing a camp-wide approach that trains staff to work directly with campers with disabilities (Hutchison, et. al., 2008). The study found that there must be mutual leadership and supportive relationships focused on inclusion to create a welcoming inclusive environment (Hutchison et al., 2008).

Clark \& Nwokah's 2010 article Play and Learning in Summer Camps for Children with Special Needs critically examines outcomes of summer camp experiences for children with special needs. The results of two national surveys indicate that inclusive and non-inclusive summer camp experiences provide benefits to campers with special needs that are similar to those experienced by typically developing youth (Clark \& Nwokah, 2010). Attendance of these camps created opportunities to increase the likelihood that children with special needs learned to view disability not as a negative condition but as a unique, positive, and integral part of them (Clark \& Nwokah, 2010). Suggesting that non inclusive camps may counterbalance a lack of disability culture that some children with special needs experience in their daily lives (Clark \& Nwokah, 2010).

A large part of the camper experience and camp culture is due to the relationship they develop with the camp counselors and their peers. Research has found that camp staff that are professionally trained can enhance the developmental experience for children at camp (Roark et al., 2010). It is important to assess the perspective of the camp counselors to identify common misconceptions, discomforts, and lack of knowledge surrounding working with children with 
hearing impairments as it directly influences the campers and culture of the camp. Information gathered through surveys and interviews can be used to develop informational training programs to help bridge the gap to increase camp counselors' abilities to work with this population of children, and to create a more natural and comfortable relationship between the camper and the counselor.

\section{Parents as a Perceived Barrier}

While it is important to review the camper's perspective, another limiting factor to social inclusion within camp settings may be due to the parent's perspective of their child's barriers. There are perceived barriers that parents have on their disabled child's participation in recreational activities (Schleien et al., 2014). Many of the parents had concerns about their child's safety and well-being when participating in the recreations offered at camp (Schleien et al., 2014). Some children with hearing impairments may have medical devices such as cochlear implants or hearing aids, and many parents often have concerns about the maintenance of the equipment while the child is participating in camp activities. Parents express concerns about the camp staff's knowledge of handling these devices. "Our son wanted to go away to summer camp like his brothers. We were hesitant because of his implant but didn't want him to miss out on that experience" (Folts, 2008. p.1). Although deaf children may excel in a mainstream classroom, parents often view residential camps — in which the child stays overnight away from home and away from their usual support network - to be a whole new challenge (Folts, 2008). Schleien's study found that parents felt more secure having their child participate in recreational activities when the environment and staff provide increased access and facilitate social inclusion in the program and activities (Schleien et al., 2014). 


\section{Chapter 3: Methods}

\section{Process and Methods}

The researcher gained approval from the University of St. Augustine for Health Sciences Institutional Review Board (IRB) committee prior to the dissemination of the surveys. The IRB is a constituted group formally designated to review and monitor research to protect the rights of human research subjects (University of St. Augustine for Health Sciences, 2020). Due to the Coronavirus (COVID-19) pandemic, virtual surveys were used in place of observation at local residential camps. Interviews were found to be unnecessary to the research conducted, as a focus group was used to review the guidebook to determine understanding of the content.

Surveys were available to any camp staff 18 and older, regardless of gender. There were no limitations on the years of experience an individual had, or time frame from last employment at camp. The mixed-method survey was approximated to take up to 30 minutes to complete. The questions consisted of open-ended, scaled, and multiple-choice answers with options to elaborate in further detail. The surveys were used to gather information about current accessibility options available at the camp, as well as counselor experience, counselor perspectives and comfort level when working with deaf and hard of hearing children.

Survey questions were based on the occupational model of Person Environment Occupation Performance (Baum, 2014). The mixed methods design of this study included qualitative open-ended questions and Likert rating scales. A mixed methods approach was used to allow for more comprehensive qualitative data. Sample survey questions for the camp counselors included: what type of adaptive equipment does this facility use and do you know how to operate it? What environmental barriers can you identify for a child with hearing impairments? How confident are you in communicating with a person with hearing impairments? 
Do you feel confident leading activities for children with hearing impairments? See appendix D for full list of survey questions.

Emails containing the link to the survey were sent to California camps, Girl Scouts of America, online camp-based Facebook groups, and the American Camp Association. The survey was also distributed by word of mouth through participants. The surveys were specifically sent to camps located around California that offer an inclusive camp program for children with disabilities. However, the survey link was open to counselors in any state and any type of camp program. The goal of the survey was to gather information from camp staff at both inclusive and disability specific camps.

Data collected from the survey was used as a needs assessment to help identify possible gaps in understanding of the deaf and hard of hearing culture and staff training when working with Deaf or hard of hearing children. The resultant information provided the researcher with areas that camp staff felt less confident or did not have a strong understanding of within the Deaf and hard of hearing culture. The researcher then applied the information into sections of the guidebook where they can be learned with more detail.

Due to the COVID-19 pandemic, this study was unable to reach the anticipated 50 survey participants as many camps were closed during the summer months, and many camp staff did not have access to their work emails. This study may have been able to reach a wider variety of participants from various types of inclusive and disability specific camps if physical observations were able to take place.

\section{Timeline}

The project duration was approximately twenty weeks; starting in July 2020, lasting until December 2020. The initial four weeks were spent completing the IRB process, doing a research- 
based needs assessment, and developing the base of the inclusion guidebook. During weeks five to sixteen of the project, the researcher developed a list of inclusionary strategies and activities to increase social inclusion and participation for campers who are hearing impaired. In week 5, a grant was provided to purchase a Kids Included Together (KIT) training program to research and develop inclusion strategies for children with disabilities in camps. During this time, the researcher compiled all relevant information, videos, and inclusion strategies, to develop the interactive digital guidebook that was disseminated to the camps counselors that have participated in the surveys, as well as other camps and sites that may benefit from the education. The educational module is geared towards the training of camp counselors, and consists of inclusion strategies, recommendations for accessibility, and basic sign language communication. Once the guidebook was published online, links were sent out to local camps, the ACA, and distributed by word of mouth to camp counselors that may benefit from the guidebook.

\section{Figure 1}

\section{Timeline of Project}

\begin{tabular}{|c|c|c|c|c|c|c|c|c|c|c|}
\hline Tasks & $\begin{array}{l}\text { Week } \\
\mathbf{1} \\
\text { (Jul 27- } \\
\text { Aug 1) }\end{array}$ & $\begin{array}{l}\text { Week } \\
\mathbf{2} \\
\text { (Aug 2- } \\
\text { Aug 8) }\end{array}$ & $\begin{array}{l}\text { Week } \\
\mathbf{3} \\
\text { (Aug 9- } \\
\text { Aug 15) }\end{array}$ & $\begin{array}{l}\text { Week } \\
\mathbf{4} \\
\text { (Aug 16- } \\
\text { Aug 22) }\end{array}$ & $\begin{array}{l}\text { Week } \\
\mathbf{5} \\
\text { (Aug 30 } \\
\text {-Sep 5) }\end{array}$ & $\begin{array}{c}\text { Week } \\
\mathbf{6} \\
\text { (Sep 7- } \\
\text { Sep 12) }\end{array}$ & $\begin{array}{l}\text { Week } \\
\mathbf{7} \\
\text { (Sep 13- } \\
\text { Sep 19) }\end{array}$ & $\begin{array}{l}\text { Week } \\
\quad \mathbf{8} \\
\text { (Sep20- } \\
\text { Sep 26) }\end{array}$ & $\begin{array}{l}\text { Week } \\
\quad 9 \\
\text { (Sep 27 } \\
\text {-Oct 3) }\end{array}$ & $\begin{array}{c}\text { Week } \\
\mathbf{1 0} \\
\text { (Oct 4- } \\
\text { Oct 10) }\end{array}$ \\
\hline \multicolumn{11}{|l|}{$\begin{array}{l}\text { Complete a needs assessment of } \\
\text { current social inclusion } \\
\text { techniques for DHH individuals } \\
\text { within a residential camp setting }\end{array}$} \\
\hline \multicolumn{11}{|l|}{ Complete IRB review } \\
\hline \multicolumn{11}{|l|}{$\begin{array}{l}\text { Develop Survey and send } \\
\text { surveys to potential participants }\end{array}$} \\
\hline $\begin{array}{l}\text { Survey and interview camp } \\
\text { counselors }\end{array}$ & & & & & & & & & & \\
\hline
\end{tabular}




\begin{tabular}{|l|l|l|}
\hline $\begin{array}{l}\text { Develop inclusion strategies to } \\
\text { be used in camps (KIT training } \\
\text { and inclusive research) }\end{array}$ & & \\
\hline $\begin{array}{l}\text { Research and promote OT's role } \\
\text { in inclusion for DHH in camps }\end{array}$ & & \\
\hline $\begin{array}{l}\text { Organize survey data } \\
\text { Develop and organize Inclusion } \\
\text { Guidebook }\end{array}$ & & \\
\hline $\begin{array}{l}\text { Create presentations and present } \\
\text { on Accessibility and Social } \\
\text { inclusion for DHH children in } \\
\text { camp. }\end{array}$ & \\
\hline
\end{tabular}

\begin{tabular}{|c|c|c|c|c|c|c|c|c|c|c|}
\hline Task & $\begin{array}{l}\text { Week } \\
\mathbf{1 1} \\
\text { (Oct } 11 \\
\text {-Oct 17) }\end{array}$ & $\begin{array}{l}\text { Week } \\
\mathbf{1 2} \\
\text { (Oct 18- } \\
\text { Oct 24) }\end{array}$ & $\begin{array}{l}\text { Week } \\
\mathbf{1 3} \\
\text { (Oct 25- } \\
\text { Oct 31) }\end{array}$ & $\begin{array}{l}\text { Week } \\
\mathbf{1 4} \\
\text { (Nov 1- } \\
\text { Nov 7) }\end{array}$ & $\begin{array}{c}\text { Week } \\
\mathbf{1 5} \\
\text { (Nov 8- } \\
\text { Nov 14) }\end{array}$ & $\begin{array}{l}\text { Week } \\
\mathbf{1 6} \\
\text { (Nov 15- } \\
\text { Nov 21) }\end{array}$ & $\begin{array}{l}\text { Week } \\
\mathbf{1 7} \\
\text { (Nov 22- } \\
\text { Nov 28) }\end{array}$ & $\begin{array}{l}\text { Week } \\
\mathbf{1 8} \\
\text { (Nov 29- } \\
\text { Dec 5) }\end{array}$ & $\begin{array}{c}\text { Week } \\
\mathbf{1 9} \\
\text { (Dec 6- } \\
\text { Dec 18) }\end{array}$ & $\begin{array}{c}\text { Week } \\
\mathbf{2 0} \\
\text { (Dec 13- } \\
\text { Dec 19) }\end{array}$ \\
\hline \multicolumn{11}{|l|}{$\begin{array}{l}\text { Complete a needs assessment of } \\
\text { current social inclusion } \\
\text { techniques for DHH individuals } \\
\text { within a residential camp setting }\end{array}$} \\
\hline \multicolumn{11}{|l|}{ Complete IRB review } \\
\hline \multicolumn{11}{|l|}{$\begin{array}{l}\text { Develop Survey and locate } \\
\text { potential participants }\end{array}$} \\
\hline \multicolumn{11}{|l|}{$\begin{array}{l}\text { Survey and interview camp } \\
\text { counselors }\end{array}$} \\
\hline \multicolumn{11}{|l|}{$\begin{array}{l}\text { Develop inclusion strategies to } \\
\text { be used in camps (KIT training } \\
\text { and inclusive research) }\end{array}$} \\
\hline \multicolumn{11}{|l|}{$\begin{array}{l}\text { Research and promote OT's role } \\
\text { in inclusion for DHH in camps }\end{array}$} \\
\hline \multicolumn{11}{|l|}{ Organize survey data } \\
\hline \multicolumn{11}{|l|}{$\begin{array}{l}\text { Develop and organize Inclusion } \\
\text { Guidebook }\end{array}$} \\
\hline $\begin{array}{l}\text { Create presentations and present } \\
\text { on Accessibility and Social } \\
\text { inclusion for DHH children in } \\
\text { camp. }\end{array}$ & & & & & & & & & & \\
\hline
\end{tabular}




\section{Chapter 4: Results and Analysis}

\section{Participant Demographics}

The survey was completed by 13 participants from various camps. Of the 13 participants, 11 were female, 1 male, and 1 transgender. Camp counselors accounted for nine of the survey participants, followed by two being a camp director, and one alternative counselor (in charge of specific camp activities. Ex: riding director). Participant ages ranged between 18-years-old and 40-years and older (see Figure 2). The average years of working at a camp totaled 8.33 years. This suggests that each of the survey participants have worked within the camp environment for multiple years, with the longest duration being 38 years. Given that each of the participants have worked at a camp longer than 1 year, suggests that all the participants are comfortable in their roles as a counselor and understand how the camp operates. All thirteen of the participants stated that their camps were inclusive camps.

\section{Figure 2}

Demographic Information

\begin{tabular}{rrrr}
\hline Gender & & Number of Participants \\
\hline & Female & \\
& Male & 11 \\
& Transgender & 1 \\
Age & & Number of participants & 1 \\
\hline & $18-20$ & & 1 \\
& $21-25$ & \\
& $26-30$ & \\
& $31-40$ & \\
& $40+$ & & 2 \\
\hline Position & & Number of Participants & \\
\hline & Counselor & 10 \\
& Director & 3 \\
\hline
\end{tabular}

Copyright (C) Tiffany L. Coles, 2020 all rights reserved 


\section{Working with Deaf and Hard of Hearing Children in Camps}

To understand how much counselors knew about the Deaf and hard of hearing culture, participants were asked questions about the communication styles they use, common assistive devices, and perceived barriers within the camp. The participants were asked if they have had experience working with children with disabilities, in which $100 \%$ of participants had. Ten participants have worked with deaf and hard of hearing children directly, while the remaining three have not (see Figure 3). The participants were then asked if they had any prior use or understanding of American Sign Language (ASL). Of the 13 participants, five could speak or understand some ASL, seven did not speak or understand ASL, and only one of the participants were fluent (see Figure 3). Nearly 500,000 Deaf individuals use ASL within the United States and Canada daily (Start ASL, 2020). For many of these individuals, sign language is their natural language, it is the way that they feel most comfortable communicating. The number of counselors found in the camp that can speak or understand even a little bit of ASL is rather low. Learning the ASL alphabet, numbers, and basic signs can greatly increase the amount of communication a counselor can have with a deaf and hard of hearing camper. The small act of learning a few basic signs can greatly improve the camper experience and make them feel more welcome and accepted.

\section{Figure 3}

Counselor's Ability to Speak ASL

\begin{tabular}{rr}
\hline Ability to speak or understand ASL & Number of Participants \\
\hline Fluent & 1 \\
Some ASL & 5 \\
Not able to speak or understand ASL & 7 \\
\hline Have worked with DHH children before & Number of Participants \\
\hline Yes & 10
\end{tabular}

Copyright (C) Tiffany L. Coles, 2020 all rights reserved 
Communication helps to form a foundation for decision making and relationship building (Melikechi, n.d.). Communicating with a deaf and hard of hearing individual is an achievable goal, even when accommodations are not available. Participants were asked to describe the means of communication they used with deaf and hard of hearing campers; in which they responded that they have used lip-reading, gesturing, writing with pen and paper, texting on a phone or tablet, using visuals, and limited ASL to communicate. All these methods are effective ways to communicate; as communication is a joint effort shared by both the deaf and hard of hearing individual and the hearing individual (Melikechi, n.d.). When asked on a Likert scale of 1 (not comfortable at all) to 10 (completely comfortable), how comfortable do you feel communicating with a person with hearing impairments? The results were varied with $55.8 \%$ of participants feeling comfortable, and $46.2 \%$ of participants feeling slightly or not at all comfortable (see Figure 4). Even when counselors are using effective means of communication, nearly half of the counselors still did not feel comfortable communicating. Overall counselor comfort level when communicating with deaf and hard of hearing campers can be increased if the campers and counselors have access to interpreters, other interpreting devices, or communications boards within the camp setting. This can allow for communication to flow easier and more naturally. Another useful strategy is for camps can develop a camp specific communication board that can be used by the camper to identify their needs to the counselors and other staff. It is always important to consult the deaf and hard of hearing camper to see what their preferred method of communicating may be as they may not feel comfortable using certain communication strategies. 


\section{Figure 4}

\section{Counselor Comfort in Communicating with Deaf and Hard of Hearing Individuals}

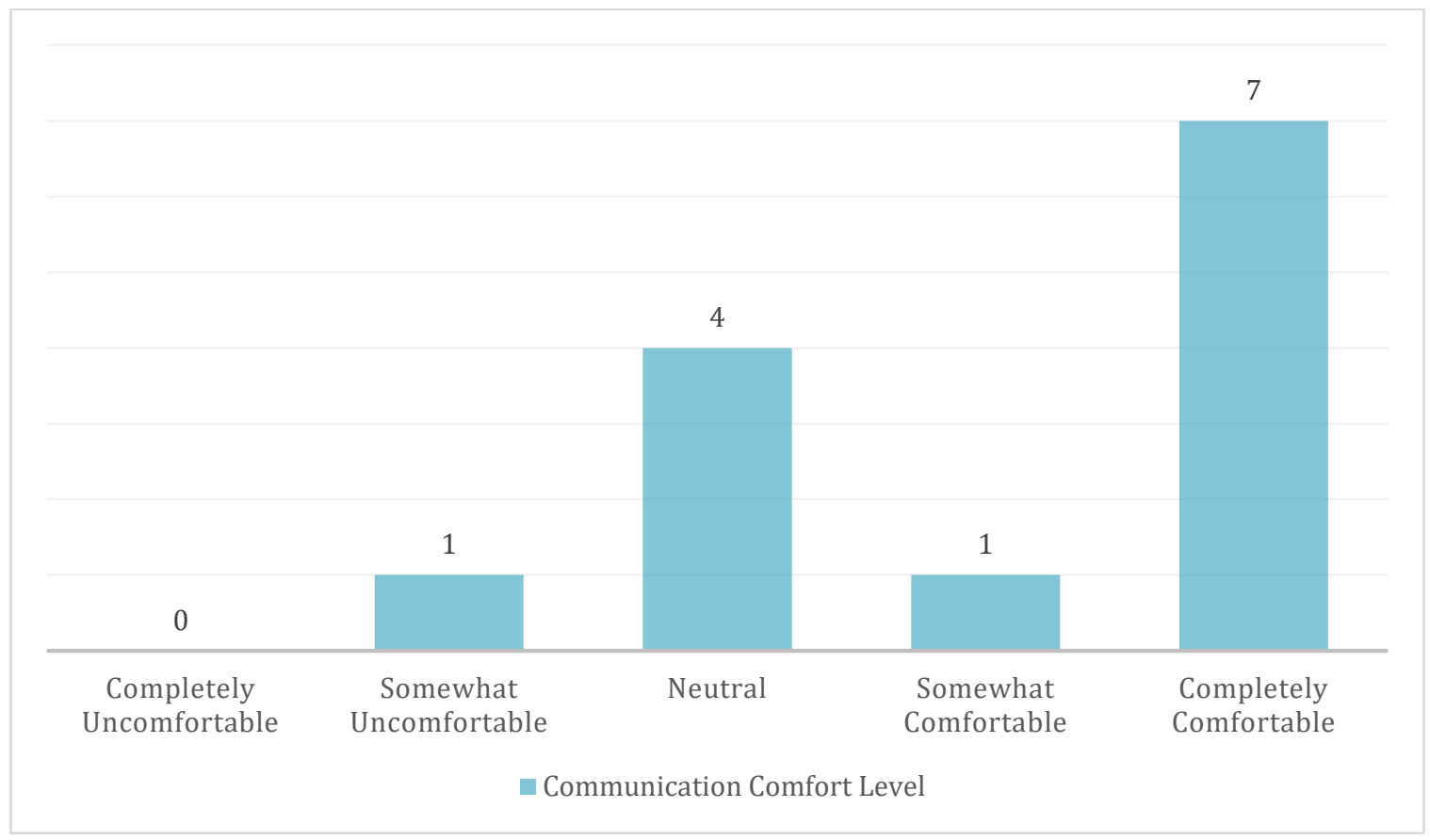

The Americans with Disabilities Act (ADA) requires any business, building, or other place that is open to the public to provide auxiliary aids and services that include qualified interpreters, note takers, and written materials (Accredited Learning Services, 2016). Participants were asked on a scale of 1 (I do not know) to 10 (I know how) if they knew the rights of a child with disabilities within the camp (standard ADA guidelines) or how to access interpreting services if needed. Many of the participants were unsure of ADA guidelines or how to access an interpreter as needed, as shown in Figures 5 and 6. Of the 13 participants, eight stated they did not know of any adaptive equipment used within the camp. The remaining five participants knew of basic ADA requirements of wheelchair ramps, flashing alarms, pool chair lifts, and ADA accessible restrooms. Of the camps that did offer adaptive equipment, only four participants knew how to operate the equipment. Phone numbers and website links to interpreter services should be posted on walls or within employee or site manuals. While businesses are financially 
responsible for providing a sign language interpreter, camps can accommodate by hiring a counselor that is proficient in sign language or providing devices that translate conversations to text in real time.

In cases of an emergency, ten survey participants stated that they did not know proper the emergency procedures for deaf and hard of hearing campers at their camp. The deficit of knowledge regarding safety requirements and emergency procedure could pose a potential danger to campers. While many state and local government emergency services offer accommodations during large scale emergencies, camps can take small measures to aid the deaf and hard of hearing camper's safety. These accommodations include storing hearing aids in places that they can be easily found if an emergency were to occur, storing paper and pens in emergency kits, and by carrying pre-printed messages such as "I use American Sign Language and need an ASL interpreter," or "If you make announcements, I will need to have them written or signed" in case emergency personnel are called in. 


\section{Figure 5}

Knowing the Rights of a Child with Disabilities at Camp

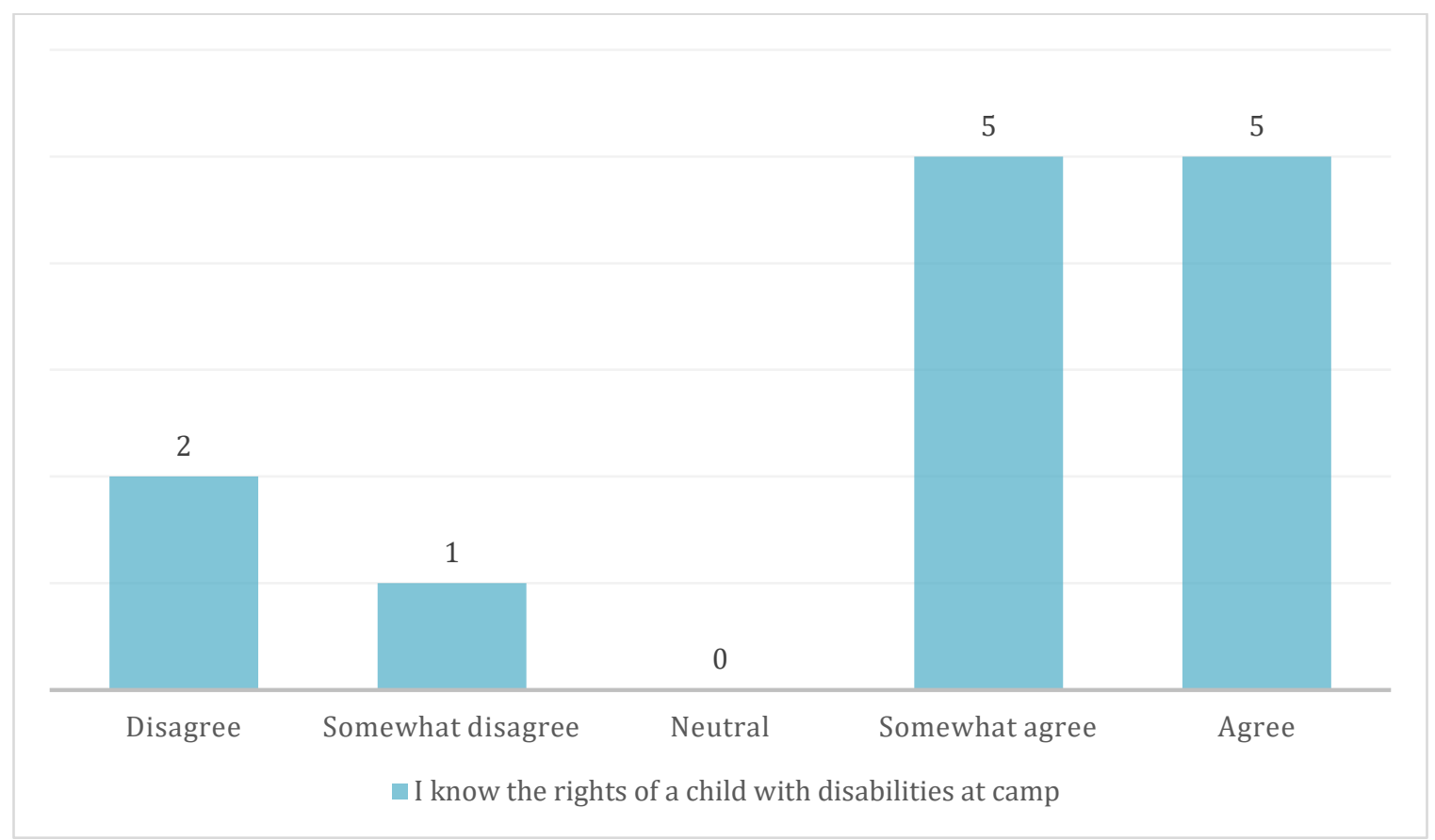

\section{Figure 6}

Knowing How to Access Interpreting Services

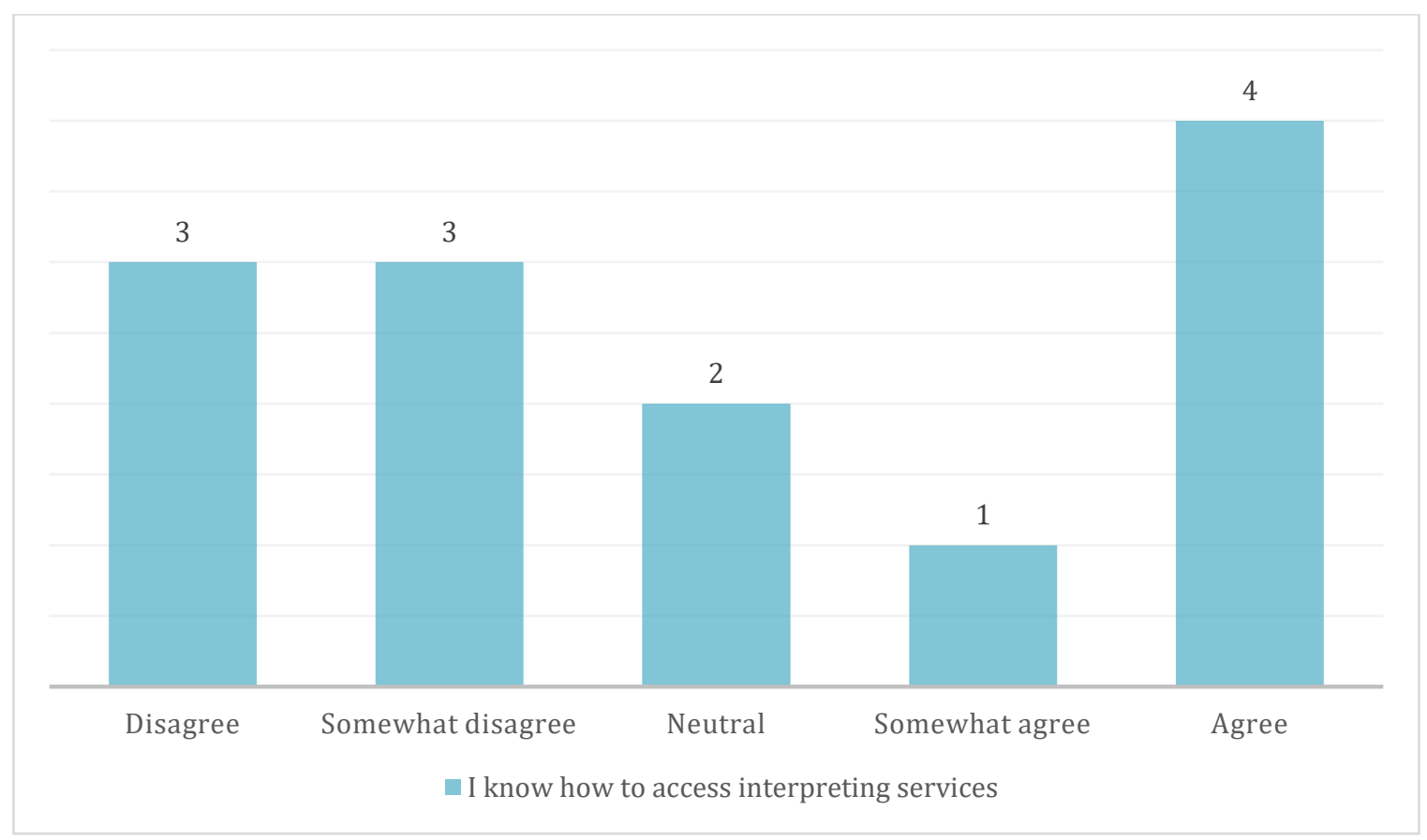

Copyright (C) Tiffany L. Coles, 2020 all rights reserved 


\section{Parents Influence on Counselors}

Due to time constraints, the impact parents have on camp counselors and the choices they made in deciding which camp their child should attend was unable to be assessed in this research study. Previous research shows that parents decide which camp their child should attend based on the needs of the child, and how well the camp is able to meet those needs. For a deaf and hard of hearing parent, the choice may be less difficult if inclusive camps are able to show competency and inclusive accommodations for their child. Participants of the survey stated that most of the counselors had minimal interactions with the parents. Mostly camp directors worked with parents, as some parents would voice their questions and concerns for their child and their needs. A former camp director, Participant E stated,

"When I was director, I was the main face for them [the parents], kids weren't allowed cell phones so if they needed to reach their child, they had to contact me first. It made for a lot of very nervous parents at drop off, many times significantly more nervous than their child!".

Offering the parents an opportunity to voice their concerns prior to the camp stay, can help to alleviate their nerves, demonstrate the camps inclusive nature, and help the counselors to plan activities accordingly.

\section{Inclusion in Camp Activities}

Camp counselors are expected to have the training and comfort level required to manage between 2-18 children at a time. When participants were asked if they felt comfortable leading activities for deaf and hard of hearing individuals the results were widely spread across a scale of 1 (not comfortable at all) to 10 (completely comfortable) (see Figure 7). 


\section{Figure 7}

\section{Counselor Comfort Level when Leading Deaf and Hard of Hearing Children}

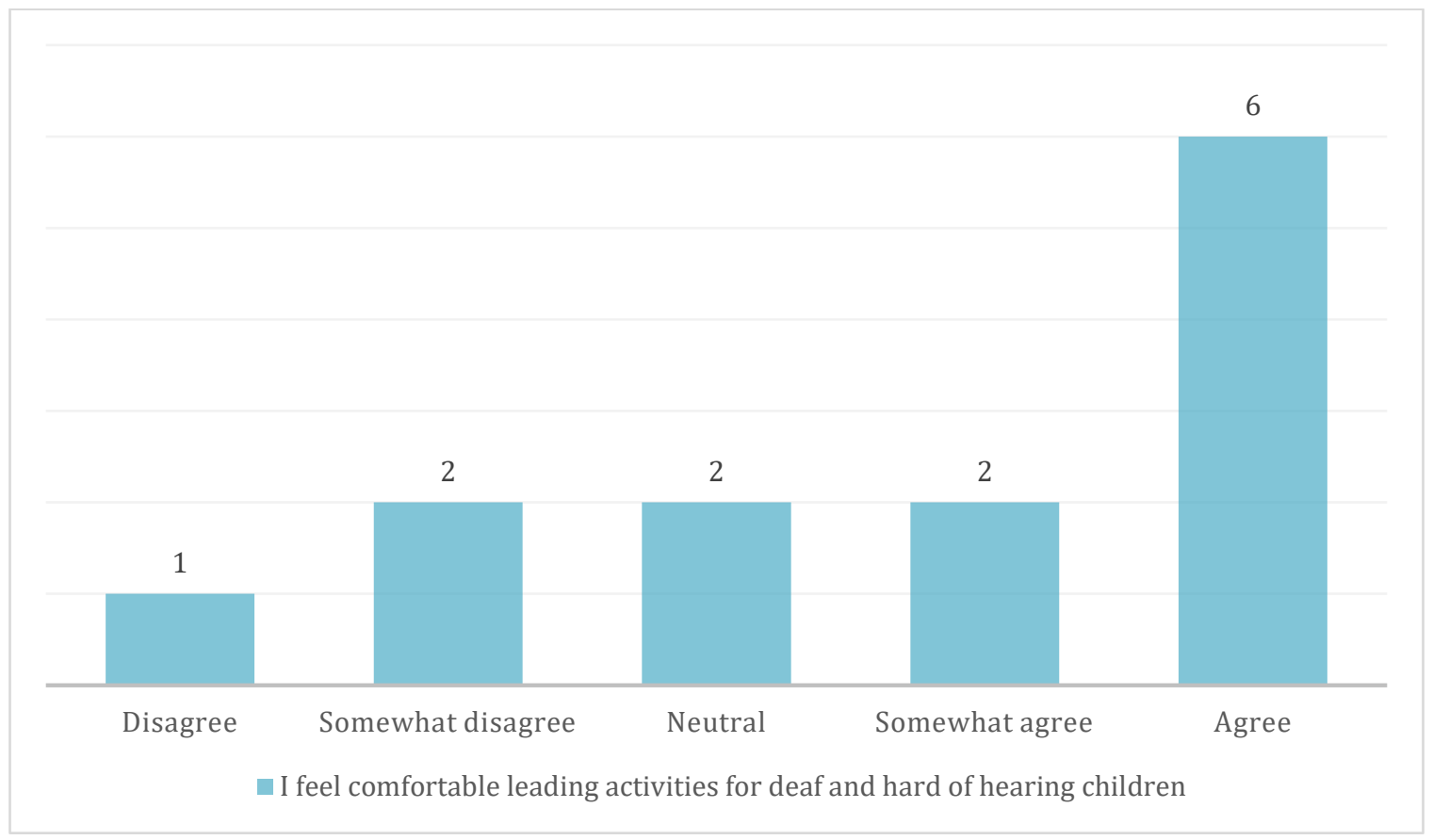

The wide range of responses concluded that several counselors did not feel comfortable or are unsure of leading activities for deaf and hard of hearing individuals. This suggests that counselors feel confident in general inclusionary practices but have limited knowledge of deaf and hard of hearing needs and accommodations. Counselor training should target these areas of weakness by educating counselors on etiquette for working with deaf and hard of hearing individuals, simple camp accommodations that can be used by counselors, and by teaching inclusive strategies for various camp activities. Inclusion can be as simple as proving visual instructions and cues when possible, offering seating closer to the speaker so the camper can see more clearly, and giving a heads-up warning when tasks are about to end. These simple tasks can make working with deaf and hard of hearing campers much less daunting and can make the camper feel that their needs are being met as well. As stated by Participant B,

"I think with staff who are educated and aware can accomplish any camp activity". 


\section{Analysis}

To analyze the qualitative data collected in this study, the Braun \& Clark (2006) approach to thematic analysis was used. This method contains the six phases to identify themes: 1) getting familiar with the data, 2) generating initial codes, 3) searching for themes, 4) reviewing the themes, 5) generating definitions and names for themes, and 6) producing a report of the analysis (Braun \& Clark, 2006).

Within Phase 1, the student researcher became familiar with the survey data by organizing and summarizing the responses by question. During phase 2 , the student researcher systematically coded the qualitative the data by highlighting and tagging keywords and phrases found within the short answers. Phase 3 was spent collating the codes into corresponding themes.

Coding was completed using an Excel spreadsheet that was organized by code word and the corresponding statement or phrase the word was found in. In total, there were 453 codes found in the data. The codes were then organized by similar qualities that defined the overall themes. For example: the emotions described in the survey responses when asked why the participant chose to become a camp counselor, were applied to the theme of counselor motivation. Four themes emerged from the coding responses. Themes included the motivation to become a camp counselor, the fact that campers model their behaviors off the counselor's actions, the need for accommodations for deaf and hard of hearing campers, and that counselors require more training to work with this population (see Figure 8).

Phase 4 consisted of reviewing themes with the student researcher, doctoral faculty, and other doctoral students. Once the themes were deemed to align with the study, the student researcher was able to move on to phase 5 . Phase 5 involved generating names and definitions of 
the corresponding themes. During phase 6, the student researcher identified statements and phrases that best represented the themes and their overall meanings.

\section{Figure 8}

Themes and Code Counts

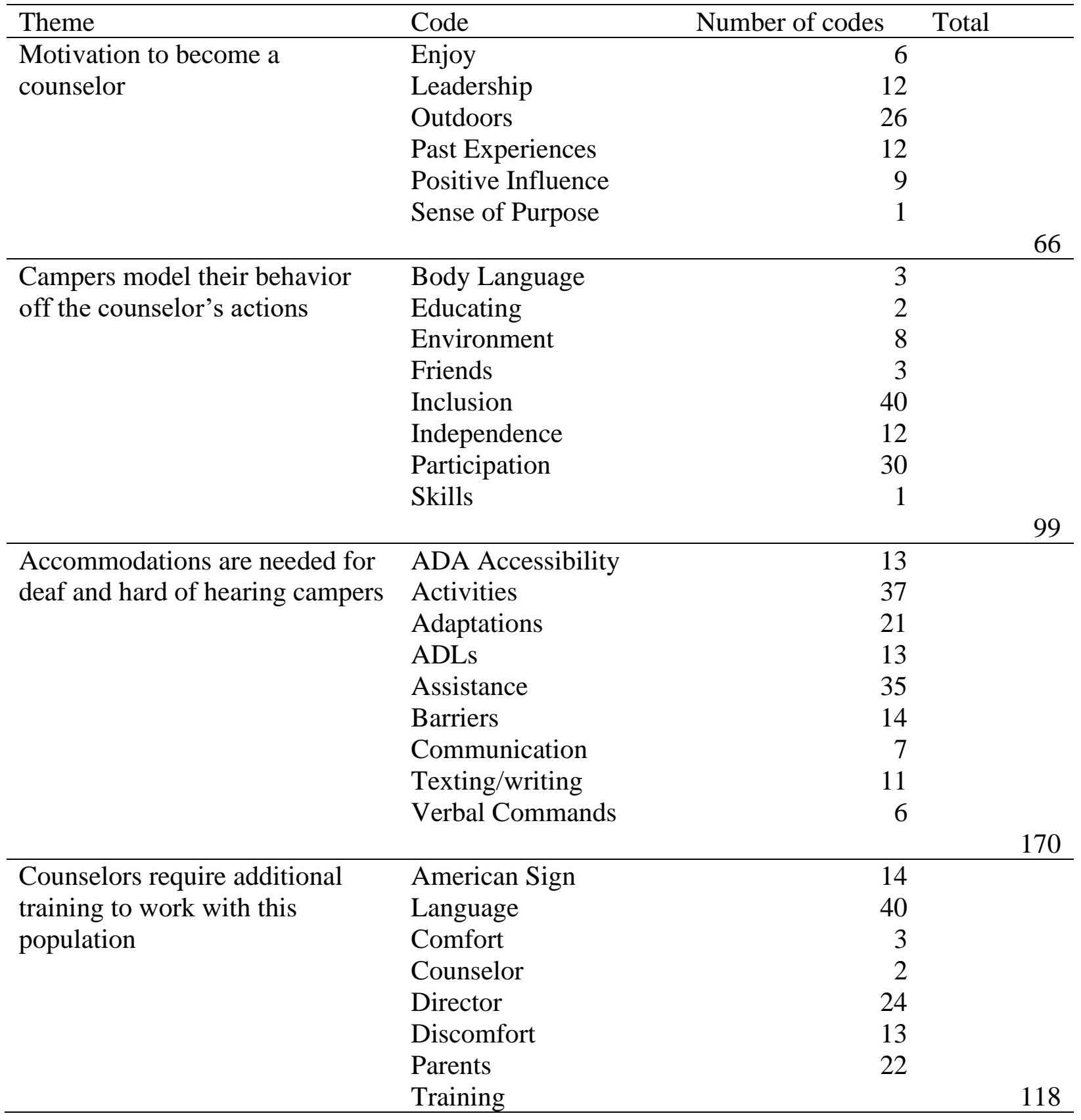

Copyright (C) Tiffany L. Coles, 2020 all rights reserved 


\section{Motivation to Become a Counselor}

To gain an understanding of the motivation to become a counselor, participants were asked why they chose to work at a camp.

Leadership. Survey responses stated that many of the counselors have had a positive experience and enjoyed camp as a child. Other responses included being influenced by friends that worked at camp, sharing their love of nature and outdoor activities, as well as having the opportunity to work with children while giving back to the community. Some stated that they enjoyed the opportunity to educate the children in attendance. Participant $\mathrm{C}$ stated,

[I became a counselor because] "it was a way to create a sense of purpose. To be a positive influence in a child's life and to work towards building a community was an amazing experience [for me]".

Common statements counselors made were that they enjoyed giving the children a chance to explore the outdoors, learn new skills, and teach the children about our natural environment and how to be responsible for it. Some participants stated that camp helps to foster a sense of independence and competence for the children that attend, while giving the counselor a sense of purpose. Survey Participant A stated,

"I'm empowering young girls to be and find themselves and their strengths."

Past Experience. The positive feedback loop created by the positive experiences had at camp becomes what the student researcher has deemed as 'The Camp Counselor Cycle'. A camper having a positive and memorable camp experience can lead the camper wanting to return the favors to other campers by coming back as a leader themselves. This in turn may motivate a 
new camper to repeat the process, as they have had positive and memorable experiences. Survey Participant D stated,

"I went to camp as a child and I wanted to give other children the same experience that I had".

This is a common reason why many campers return to the same camp year after year, as they have made childhood friends and have positive role-models to model their actions off. This symbiotic relationship allows both campers and camp staff to develop social skills, leadership skills, and develop a sense of purpose.

\section{Campers Model Behaviors Off Counselors}

Camp counselors may be some of the most influential people in a young person's life (The Power of Camp, 2017). Counselors play a distinct role in the camp setting as they are leaders, mentors, mediators, and parents-away-from-home (The Power of Camp, 2017).

Inclusion. The camp counselor's behavior and actions play heavily into the camper's experience, as the camper observes how the counselor interacts with other campers and staff during positive and negative events. As shown in Figure 9, many counselors agree that their actions are being modeled by the campers. The counselor sets the precedent for the next generation by showing them how to serve others with inclusion and respect, how to work hard, and develop leadership skills. To create a truly inclusive environment, the counselors must understand the definition of inclusion, how to identify barriers to inclusion, and how to demonstrate inclusive tendencies within their actions. Survey participant I defined inclusion as, "making every single camper feels included. [And] that no camper - with or without disabilities, has to feel like they can't do the same thing everybody else is doing". 


\section{Figure 9}

\section{Campers Modeling Behaviors}

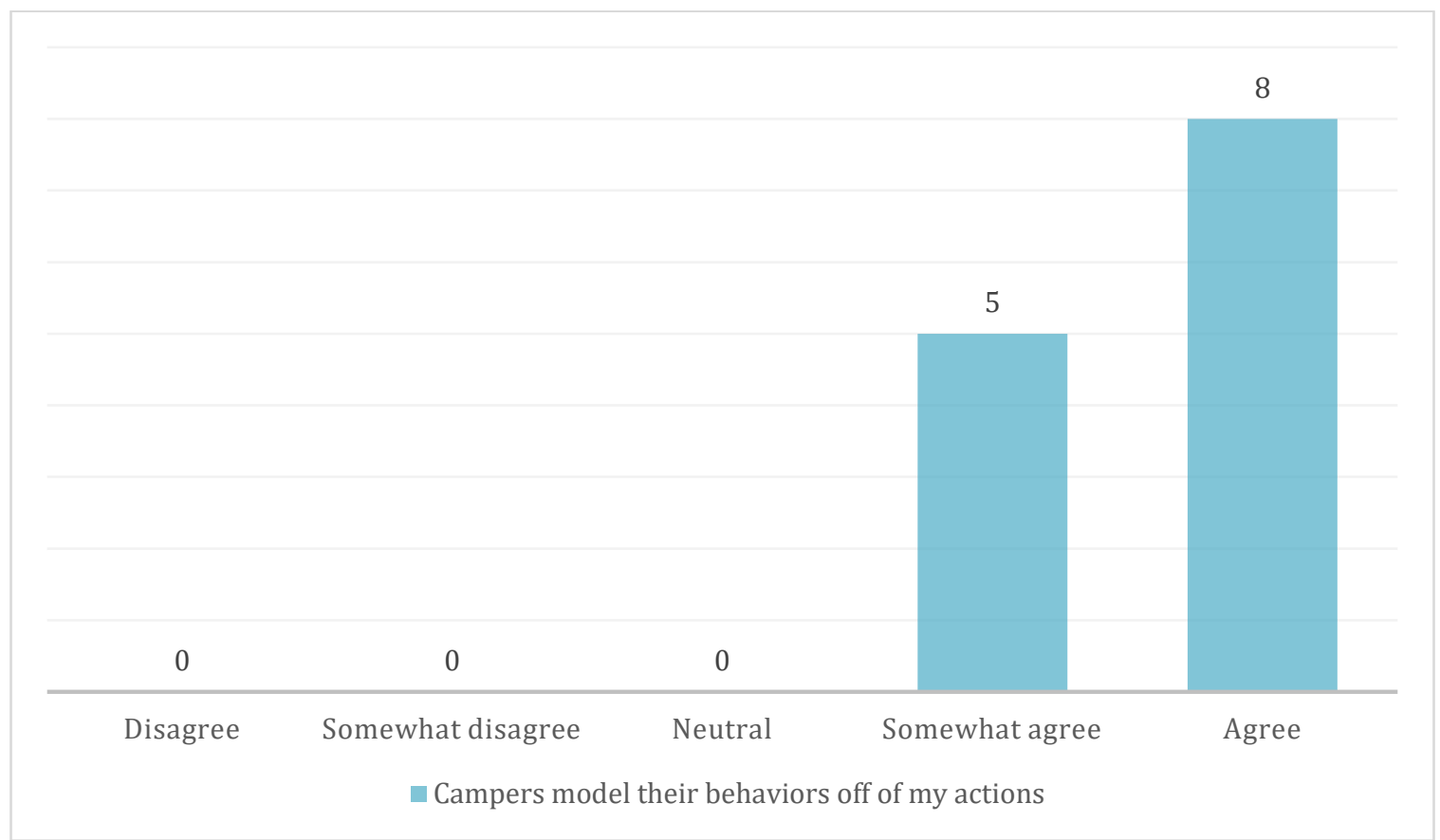

Counselors that are properly trained on inclusion for deaf and hard of hearing children will use people-first language, be able to anticipate differences and plan for inclusion; will focus on the child's ability and not their disability and provide accommodations when needed. By displaying these inclusive actions, the campers will pick and learn these behaviors and begin to use these techniques when interacting with their peers inside and out of the camp environment.

Body Language. Within the deaf and hard of hearing community, body language is extremely important. Body language is seen throughout our eyes, eyebrows, mouth, cheeks and all the way down to our elbows, bellies, and feet. The actions of our bodies can indicate our underlying intentions and feelings. Children that are deaf or hard of hearing largely rely on body language to communicate. A counselor may be saying all the right things, but if their body language is closed off or nervous when communicating or leading, the camper is going to pick up on those signals and start to feel nervous or uncomfortable as well. It is important that 
counselors, and all camp staff, pay attention to their bodies and actions to always be aware of how they may or may not be portraying inclusion. If the counselor feels comfortable and confident when communicating or leading a deaf or hard of hearing child, the deaf or hard of hearing child will in turn feel more comfortable and confident being in that environment.

\section{Accommodations Needed within the Camp}

Just as any inclusive camp would accommodate for children with disabilities, physical and social accommodations may be needed to best include the deaf and hard of hearing population.

Adaptation. Deaf and hard of hearing children can benefit from simple accommodations that can be provided at little to no cost. The first being that counselors understand how to create an inclusive environment. "Everyone gets to take part in the experience that is camp, no matter what differences they might have" (Survey Participant C). Inclusive practices mean that counselors provide every camper with the opportunity to play and excel in every activity, while anticipating differences and planning for inclusion (The Power of Camp, 2017). Creating an inclusive environment is a team effort, all staff must be on board and demonstrate inclusive behaviors. This can be accomplished by using "people first language", focusing on the child's abilities, anticipating differences, asking the camper directly what they may need to feel included, and using the parents as a resource. Along with physical accommodations such as flashing alert systems, vibrating watches or alarms, and interpreting devices; the camper is sure to feel welcome and included within the camp.

This study found that camp staff are not adequately trained on working with deaf and hard of hearing campers within the residential camp setting. Nor do camp staff feel prepared to work with a deaf and hard of hearing person in the camp setting. Survey responses found that 
counselors lacked the knowledge of available adaptive equipment and accommodations available at their camps. Of the 13 participants, nine did not know how to operate the adaptive equipment found in the camp (see Figure 10). Six of the 13 survey responses stated, "I don't know". Whereas one survey participant (Participant K) stated,

"Some camps had nearly none [adaptive equipment] beyond ADA residential facilities, the last camp I worked at was designed with adaptations in mind, so there are lots of ramps and wide doorways. All fire alarms also had the bright flashing lights. One of the camps we hosted was for kids with hearing impairments, and many of them had cochlear implants."

\section{Figure 10}

Counselor's Understanding of Adaptive Equipment Operation

\begin{tabular}{rrr}
\hline $\begin{array}{c}\text { Do you know how to operate the } \\
\text { adaptive equipment found in your } \\
\text { camp? }\end{array}$ & Number of Participants & \\
\hline Yes & 4 \\
No & 9
\end{tabular}

Further Counselor Training is Needed

The study found that overall, counselors feel confident in their abilities to lead children in camp activities and find ways to be inclusive. However, when it comes to working with the deaf and hard of hearing population, that confidence level begins to diminish. This may be a result of the fact that many deaf and hard of hearing children tend to attend disability specific camps over inclusive camps, which means less exposure to this population for counselors. Or it could mean that families of deaf and hard of hearing children do not feel that the camp or staff are properly equipped to meet the needs of their child. Thus, making further training necessary.

Training. Counselors can benefit from various types of training to increase their confidence in working with the deaf and hard of hearing population. Depending on the child's Copyright (C) Tiffany L. Coles, 2020 all rights reserved 
level of hearing loss, the child may wear hearing assistive devices to increase their hearing capability. Counselors may be asked to help in caring for or maintenance the device. At some camps, the camper is responsible for caring for their device throughout the duration of their camp stay, while other camps have the camp counselor collect the devices at night. It is important for counselors to have a basic understanding of how these devices operate. Nine of the 13 participants have seen or worked with a hearing aid or cochlear implant before, whereas one participant knew the proper maintenance required for the devices (see Figure 11). While it is important for children to learn how to maintain their own hearing assistive devices, counselors should understand the basics of changing a battery or cleaning the ear channels to assist the child while gradually reducing their assistance as the child becomes more adept with the task.

\section{Figure 11}

Counselor's Understanding of Hearing Devices

\begin{tabular}{|c|c|}
\hline $\begin{array}{l}\text { Have you seen or worked with a } \\
\text { hearing aid or Cochlear Implant? }\end{array}$ & Number of Participants \\
\hline Yes & $\overline{9}$ \\
\hline No & 4 \\
\hline $\begin{array}{c}\text { Do you know how to properly } \\
\text { maintain a hearing aid or Cochlear } \\
\text { Implant? }\end{array}$ & Number of participants \\
\hline Yes & $\overline{1}$ \\
\hline No & 12 \\
\hline
\end{tabular}

Additional training should be provided to learn inclusive strategies for various camp activities, how to access and use various communication devices and adaptive equipment, and overall inclusionary techniques. Having staff educated on various types of disabilities may prove to be beneficial in providing a truly inclusive camp. 
Comfort. While the presence of occupational therapists in the camp setting is an emerging area of practice, they can help to reduce the physical and social emotional barriers present in camps. Occupational therapists have the tools and skills needed to help develop camp programs that are comfortable, restorative, socially inclusive and therapeutic for children with disabilities. Occupational therapists may help to aid counselor comfort levels as they can help identify and adapt any physical and social barriers that may be present in the camp environment.

\section{Discussion}

\section{Chapter 5: Discussion and Conclusion}

Research on this topic is limited, as many studies focused on children with motor or behavioral disabilities. Links to other research has found limited communication to be a major factor in barriers for deaf and hard of hearing children's participation in inclusive camps. Within the camp environment, deaf and hard of hearing children are limited in participation by certain accessibility accommodations, and the ability for staff and their peers to communicate with them. Through proper accommodations, inclusive adaptations and further counselor training, children that are deaf or hard of hearing may have increased camp experiences. Residential camp settings should focus on inclusion while targeting equal participation in activity, communication, and social acceptance of individuals with hearing impairments. To achieve this goal, various strategies of policy and program development, that are founded on the principles of social inclusion should be utilized. Such strategies can include the use of the Inclusion Guidebook developed from this study (Coles, 2020). Through the implementation of the inclusion guidebook into counselor orientation, counselors will feel more prepared and knowledgeable when working within the Deaf and hard of hearing community (see Appendix E). 


\section{OT Implications}

The role of an occupational therapist in a residential camp is still a relatively new area of practice. However, occupational therapists have the skills needed to develop camp programs that are comfortable, restorative, socially inclusive and therapeutic for children and adolescents of all ages and abilities. Occupational therapists that specialize in hearing impairment may be able to provide counselors with assistance with medical equipment and maintenance, as well as developing inclusive activities to promote independence, self-confidence, and helping children learn to form strong bonds with their peers. The role of an occupational therapist in a camp setting is virtually endless.

Using the Person-Environment-Occupation-Performance (PEOP) model, occupational therapists can delve further into how the people, environment, and performance impact the camper (Baum et. al., 2015). There is potential to see how hearing impairments may limit camper participation in certain camp activities such as camp songs, or hiking, or during group games. As hearing impairment is a vestibular issue, children with hearing impairments may have a poorer sense of balance. This is an opportunity to see how impaired balance may affect the child's ability to participate in gross motor activities such as a ropes course, or horseback riding. Another potential research opportunity is to interview the campers to see what kind of effect the camp environment and camp staff have on their camp experience, and if they feel that they learn developmental skills that can be applied outside of the camp environment.

\section{Envisioned Next Steps}

This capstone project has potential to become an in-person hand-on training that can address the physical and social needs of deaf and hard of hearing children through evaluation of the environmental and social aspects of residential camps. This training would be beneficial to be 
provided by an occupational therapist to counselors as a part of their orientation. The hands- on training can include learning camp-based words and camp songs in American Sign Language. Experiences can also include how to change a hearing aid battery, cleaning a cochlear implant, role playing social scenarios. As well as empathy training through trying certain activities with hearing occluded. Training can include self-care-based adaptations, such as providing labels on the food served in the cafeteria. As well as determining other physician barriers that may be present in the camp environment.

Further research can also be completed as this study was not able to gather perspectives of the parents or deaf and hard of hearing children. Follow up interviews or surveys may also be beneficial to gather the counselor's perspectives after reading the guidebook. This can be used to see if the counselor's comfort level and communication increases. It may be beneficial to gather a more conclusive perspective from counselors that work in predominantly deaf and hard of hearing populations to gather how their perspective may differ from counselors in inclusive environments.

\section{Conclusion}

This study aimed to identify the accessibility and social barriers of deaf and hard of hearing children in camps, in addition to gaining the perceived perspectives of the counselors when working with this population. This study was able to identify the gaps in counselor training that may contribute to a low attendance rate of deaf and hard of hearing children within inclusive camps. This project supports increased involvement of occupational therapists, and counselor training within the camp setting, and particularly with children with hearing impairments. Further research is needed to gather the camper perspective to further identify any barriers to deaf and hard of hearing children's participation and attendance in inclusive residential camps. 


\section{References}

Accredited Language Services (2016). When is Sign Language Interpreting Required by Law? https://www.accreditedlanguage.com/interpreting/when-is-sign-language-interpretingrequired-by-law/

American Camp Association. (2017). ACA Facts and Trends.

https://www.acacamps.org/press-room/aca-facts-trends

American Camp Association (2015). Benefits of Camp.

https://www.acacamps.org/campers-families/because-camp/benefits-camp

American Occupational Therapy Association (2017). Occupational therapy practice framework:

Domain and Process (3rd Edition). American Journal of Occupational Therapy, 68

(Supplement_1), S1-S48. https://doi.org/10.5014/ajot.2014.682006

Batten, G., Oakes, P. M., \& Alexander, T. (2014). Factors Associated with Social Interactions Between Deaf Children and Their Hearing Peers: A Systematic Literature Review. The Journal of Deaf Studies and Deaf Education, 19(3), 285-302.

https://doi.org/10.1093/deafed/ent052

Baum, C. M., Christiansen, C. H., \& Bass, J. D. (2015). The Person-Environment-OccupationPerformance (PEOP) model. In C. H. Christiansen, C. M. Baum, \& J. D. Bass (Eds.), Occupational therapy: Performance, participation, and well-being (4th ed., pp. 49-56). Thorofare, NJ: SLACK Incorporated.

Bialeschki, M. D., Henderson, K. A., \& James, P. A. (2007). Camp Experiences and Developmental Outcomes for Youth. Child and Adolescent Psychiatric Clinics of North America, 16(4), 769-788. https://doi.org/10.1016/j.chc.2007.05.011

Brannan, S., Arick, J., Fullerton, A., \& Harris, J. (1997). Inclusionary Practices: A Nationwide 
Survey of Mainstream Camps Serving All Youth (No. 0740-4131; pp. 32-34). Camping Magazine. http://prx-

usa.lirn.net/login?url=http://search.ebscohost.com/login.aspx?direct=true \&db=eric\&AN=EJ $\underline{539939 \& \text { site }=\text { eds-live }}$

Braun, V. and Clarke, V. (2006) Using thematic analysis in psychology. Qualitative Research in Psychology, 3 (2). pp. 77-101. ISSN 1478-0887

Canadian Association of Occupational Therapy (n.d.). Occupational Therapy and Social Inclusion. https://www.caot.ca/document/4069/Social\%20Inclusion\%20\%20Fact\%20Sheet.pdf

Center for Hearing and Communication [CHC] (n.d.). Statistics and facts about hearing loss. https://chchearing.org/facts-about-hearing-loss/

Coles, T. (2020). Camp Counselors Guide to Inclusion Within Residential Camps for Children That Are Deaf and Hard of Hearing. FlipSnack. https://app.flipsnack.com/details/hi0zyask9s/

Clark, M. K., \& Nwokah, E. E. (2010). Play and Learning in Summer Camps for Children with Special Needs. American Journal of Play, 3(2), 238-261. ERIC - EJ1070239 - Play and Learning in Summer Camps for Children with Special Needs, American Journal of Play, $\underline{2010 .}$.

Crompton, J. L., \& Sellar, C. (1981). Do Outdoor Education Experiences Contribute to Positive Development in the Affective Domain? The Journal of Environmental Education, 12(4), 21-29. https://doi.org/10.1080/00958964.1981.9942638

D’Eloia, M. H., \& Price, P. (2018). Sense of belonging: Is inclusion the answer? Sport in Society, 21(1), 91-105. https://doi.org/10.1080/17430437.2016.1225819 
Devine, M. A., Piatt, J., \& Dawson, S. L. (2015). The Role of a Disability-Specific Camp in Promoting Social Acceptance and Quality of Life for Youth with Hearing Impairments. Therapeutic Recreation Journal, 49(4), Article 4. https://doi.org/10.18666/TRJ-2015-V49$\underline{\text { I4-6240 }}$

Devine, M., \& Parr, Mary G. (2008). “Come on in, but not too Far:” Social Capital in an Inclusive Leisure Setting. Leisure Sciences, 30(5), 391-408. 10.1080/01490400802353083

Donnelly, P., Coakley, J. J., \& Laidlaw Foundation. (2002). The role of recreation in promoting social inclusion. Laidlaw Foundation.

Folts, D. K. (2008). Summer programs provide deaf children with a different perspective. The Hearing Journal, 61(5), 49. https://doi.org/10.1097/01.HJ.0000318965.38108.26

Hall, A., Dunlap, T., Causton-Theoharis, J., \& Theoharis, G. (2013). The Power of the Inclusive Camp Experience. American Camp Association. https://www.acacamps.org/resourcelibrary/camping-magazine/power-inclusive-camp-experience

Henderson, K. A. (2012). Peer Relationships and Camps. ACA Briefing Paper Series, 3. Hocking, C. (2017). Occupational justice as social justice: The moral claim for inclusion. Journal of Occupational Science, 24(1), 29-42. https://doi.org/10.1080/14427591.2017.1294016

Hutchison, P., Mecke, T., \& Sharpe, E. (2008). Partners in Inclusion at a Residential Summer Camp: A Case Study. Therapeutic Recreation Journal, 42(4), 181-198.

$\underline{\text { Partners in Inclusion at a Residential Summer Camp: A Case Study | Hutchison }}$

Therapeutic Recreation Journal (sagamorepub.com)

ID Tech (n.d.). 11 Benefits of summer camp. https://www.idtech.com/blog/benefits- of-summer-camp-infographic 
Kamil, R. J., \& Lin, F. R. (2015, February). The Effects of Hearing Impairment in Older Adults on Communication Partners: A Systematic Review. American Academy of Audiology. https://doi.org/info:doi/10.3766/jaaa.26.2.6

Knapp, D., Devine, M. A., Dawson, S., \& Piatt, J. (2015). Examining Perceptions of Social Acceptance and Quality of Life of Pediatric Campers with Physical Disabilities. Children's Health Care, 44(1), 1-16. https://doi.org/10.1080/02739615.2013.870041

Knebel, B. (2018, 15). The Role of Occupational Therapy in Inclusion. Bear Power. https://blogs.missouristate.edu/bearpower/2018/03/15/the-role-of-occupational-therapy-ininclusion/

Markgraf, B. (2016). The Role of Occupational Therapy in Community Based Recreation for Children and Adults with Disabilities. 1- 47. https://commons.pacificu.edu/work/sc/c8c6abe8-b9c3-48eb-8a57-103d94b2ff08

McKee, M., Schlehofer, D., \& Thew, D. (2013). Ethical Issues in Conducting Research with Deaf Populations. American Journal of Public Health, 103(12), 2174-2178. https://doi.org/10.2105/AJPH.2013.301343

Melikechi, L. (n.d.). A Camp for Everyone! United Cerebral Palsy of Delaware, Inc. http://ucpde.org/wp-content/uploads/2015/06/a-camp-for-everyone-a-guide-to-includingchildren-of-all-abilities-in-summer-camp-programs.pdf

Moderow, E., \& Tollefson, H. (2018). The Perspective of Counselors on Occupational Therapy at a Residential Camp for Children with Disabilities. 74.

Monke, A. (2018). What's the Best Age for Camp? American Camp Association. https://www.acacamps.org/campers-families/parent-blog/whats-best-age-camp

Munoz-Baell, I. M., \& Ruiz, M. T. (2000). Empowering the deaf. Let the deaf be deaf. Journal 
of Epidemiology \& Community Health, 54(1), 40-44. https://doi.org/10.1136/jech.54.1.40

Na. (2020). Community and Culture-Frequently Asked Questions. National Association of the Deaf. https://www.nad.org/resources/american-sign-language/community-and-culturefrequently-asked-questions/

Papaioannou, C., \& Evaggelinou, C. (2014). The effect of a disability camp program on attitudes towards the inclusion of children with disabilities in a summer sport and leisure activity camp. International journal of special education, 29(1), 9.

https://eric.ed.gov/?id=EJ1033944

Pereira, R. B. (2017). Towards inclusive occupational therapy: Introducing the CORE approach for inclusive and occupation-focused practice. Australian Occupational Therapy Journal, 64(6), 429-435. https://doi.org/10.1111/1440-1630.12394

The Power of Camp (2017). The Impact of a Camp Counselor. http://thepowerofcamp.com/impact-camp-counselor/

Riley, B., Stoffel, A., Landa, J., \& Schefkind, S. (2017). Early Childhood Inclusion and Occupational Therapy (OT): Maximizing Participation for Young Children and their Families. https://www.aota.org/ /media/Corporate/Files/AboutOT/consumers/Youth/ECInclusion-and-OT-brochure-20171108.pdf

Roark, M. F., Ellis, G. D., Wells, M. S., \& Gillard, A. (n.d.). Measuring Relationships between Camp Staff and Camper Developmental Outcomes: An Application of Self-Determination Theory. 17.

Schleien, S. J., Miller, K. D., Walton, G., \& Pruett, S. (2014). Parent Perspectives of Barriers to Child Participation in Recreational Activities. Therapeutic Recreation Journal, 48(1), 6173.https://js.sagamorepub.com/trj/article/view/3656\#: :text=Parent\%20Perspectives\%20of 
\%20Barriers\%20to\%20Child\%20Participation\%20in,community\%20participation\%2C\%20 socialization $\% 2 \mathrm{C} \% 20$ and $\% 20$ overall $\% 20$ quality $\% 20$ of $\% 20$ life.

Start ASL (2020). American Sign Language. https://www.startasl.com/american-sign-language/

Tsakiropoulou, E., Konstantinidis, I., Vital, I., Konstantinidou, S., \& Kotsani, A. (2007). Hearing aids: Quality of life and socio-economic aspects. Hippokratia, 11(4), 183-186.

https://pubmed.ncbi.nlm.nih.gov/19582191/

University of St. Augustine for Health Sciences (2020). Institutional Review Board. https://my.usa.edu/ICS/Academics_2017-08-22T17-14-45-332/IRB/

World Health Organization (n.d.). Deafness and hearing loss. https://www.who.int/news-room/fact-sheets/detail/deafness-and-hearing-loss 
Appendix A

IRB Approval

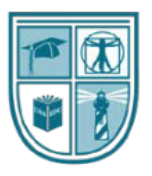

\section{UNIVERSITY OF ST. AUGUSTINE}

\section{F O R R H E A L T H S C I E N C E S}

To:

Dr. Susan MacDermott, Principal Investigator

From: $\quad$ Elizabeth Ardolino, PT, MPT, PhD

Date: $\quad$ November 16, 2020 - Exempt Review

Re: $\quad$ IRB EXEMPT Protocol Application Amendment

The protocol number is \# 0807-20

\section{RE: IRB \#0807-20}

"Exploring Accessibility and Social Inclusion for Deaf and Hard of Hearing Children in Residential Camps Through the Occupational Therapy Lens"

Dear Dr. MacDermott,

The Institutional Review Board (IRB), is responsible for the review of research involving human subjects, has reviewed and approved the amendment to your proposal that you requested on November 9, 2020. The amendment change included: Changing the title of the study. To adhere with cultural appropriateness within the Deaf and Hard of Hearing population, we are requesting the title of this research to be changed from 'Exploring Accessibility and Social Inclusion for Children with Hearing Impairments in Residential Camps Through the Occupational Therapy Lens' to 'Exploring Accessibility and Social Inclusion for Deaf and Hard of Hearing Children in Residential Camps Through the Occupational Therapy Lens'. The original application was approved on September 16, 2020.

Please contact me if you have any questions.

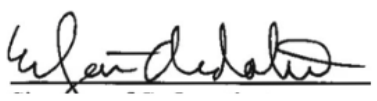

Sincerely,

Elizabeth Ardolino

University IRB Chair

Office: (737) 202-3343

Email: eardolino@usa.edu 


\title{
Appendix B
}

\author{
Email and Social Media Script
}

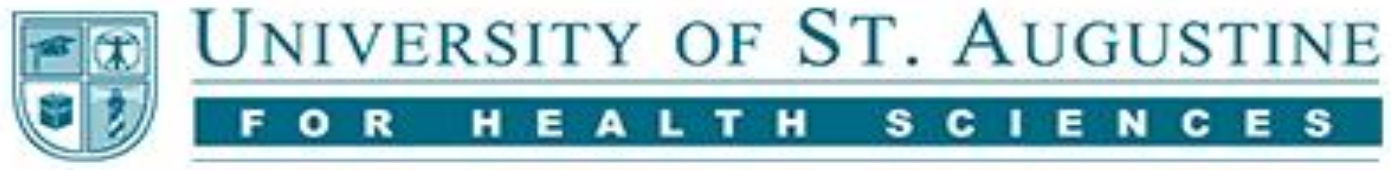

To whom it may concern,

My name is Tiffany Coles and I am an occupational therapy doctorate student at the University of St. Augustine at the San Marcos, California campus. I am currently working on my OTD capstone project in the area of accessibility and social inclusion for hearing-impaired children in residential camps. When conducting a review of current research and literature, I noticed that there is limited research of the perceptions of camp counselors when working with children with hearing impairments. Specifically, I am conducting research to learn about available accessibility resources for individuals with hearing impairment at residential camps. This study will also examine camp counselor comfort when working with this population. I am seeking to gather information about camp counselor's knowledge and comfort level when working with individuals with hearing impairments, what accessibility resources may be available to them, and how to create a socially inclusive environment. This project will be completed through the lens of an occupational therapist to assess our role in creating more physically and socially inclusive environments in all residential camps, not just in inclusive and disability-specific camps.

The information gathered from the survey will be used to create an educational program that will provide communication strategies, social inclusion techniques, and recommendations for increased accessibility for camp counselors to utilize for individuals with hearing impairments. If you would like to receive follow-up information regarding this study, please respond to this email acknowledging that you would like to receive the final product.

This survey will take approximately $30 \mathrm{mins}$ to complete and is anonymous and entirely voluntary.

Please feel free to contact me with any questions or concern. I look forward to your participation in the survey

Survey Link: https://forms.gle/i5qx7FxMsrgYUhJE6 
Sincerely,

Tiffany Coles, OTDS

University of St. Augustine, San Marcos

t.coles@usa.edu

THIS PROJECT HAS BEEN REVIEWED BY THE UNIVERSITY OF ST. AUGUSTINE FOR HEALTH SCIENCES INSTITUTIONAL REVIEW BOARD FOR THE PROTECTION OF HUMAN SUBJECTS.

IF YOU HAVE QUESTIONS OR CONCERNS, PLEASE CONTACT THE INSTITUTIONAL IRB CHAIR, DR. ELIZABETH ARDOLINO, EMAIL: EARDOLINO@USA.EDU, PHONE:

737-202-3343. 


\section{Appendix C}

\section{Survey Consent}

\section{CONSENT FOR RESEARCH PARTICIPATION}

You are being asked to participate in a research study. The box below highlights key information about this research for you to consider when making a decision whether or not to participate. Carefully consider this information and the more detailed information provided below the box. Please ask questions about any of the information you do not understand before you decide whether to participate.

\section{Key Information for You to Consider}

- Voluntary Consent. You are being asked to volunteer for a research study. It is up to you whether you choose to participate or not. There will be no penalty or loss of benefits to which you are otherwise entitled if you choose not to participate or discontinue participation.

- Purpose. The purpose of this research is to gather information about camp counselor's knowledge and comfort level when working with individuals with hearing impairments, what accessibility resources may be available to them, and how to create a socially inclusive environment.

- Duration. It is expected that your participation in this survey will last approximately 30 minutes, should you choose to participate in the survey.

- Procedures and Activities. You will be asked to complete a 46-question survey. You will be presented with an option to provide contact information if you would like to participate, on a later date, in a virtual interview or phone call that will be audio recorded. Participation in the interview is not required.

- Risks. There is a risk of loss of confidentiality with your participation in this survey. Person information will be stored in a password protected document.

- Benefits. There are no direct benefits to gain from participation in this study but the researchers hope to learn how to better support counselors that work with individuals with hearing loss in residential camps.

- Alternatives. Participation is voluntary and the only alternative is to not participate.

\section{Why is this research being done?}

The research information will be used to gather information about camp counselor's knowledge and comfort level when working with individuals with hearing impairments, what accessibility resources may be available to them, and how to create a socially inclusive environment. This project will be completed through the lens of an occupational therapist to assess our role in creating more physically and socially inclusive environments in all residential camps, not just in inclusive and disability-specific camps.

\section{What Will Happen in This Research Study?}

Participation will begin with completion of consent in virtual survey. You will be asked to complete the survey in one sitting, as there are no options to save and return to the survey. If you 
opted to participate in a follow-up interview you will be contacted by email after the survey closes to schedule your interview.

Ways that your information will be protected, as well as your privacy and confidentiality are described in a separate section later in this form.

Risks and Discomforts

There is a risk of loss of confidentiality with your participation in this survey. Personal information will not be required to complete the survey. All names and email addresses provided will be stored in a password protected document saved to the researcher's personal computer. If you decide that you want to stop being in the study, we ask that you let us know. If you stop early, we can reschedule the rest of the interview another time if needed. You are free to stop at any time.

Potential Benefits

You will receive no direct benefit from being in this study. Your being in this study may help the investigators learn the barriers or benefits that camp counselors have on the impact of children with hearing impairment's occupations and meaningful activity when attending residential camps.

Costs

There are no costs to you for being in this research study.

\section{Payment}

You will not be paid for being in this study.

\section{Confidentiality}

We will not record any information that shows your identity. Your name will only be used to contact you for scheduling of the interview. Your name will not appear in the research in any way.

We will store your information in ways we think are secure. We will store electronic files in computer systems with password protection. However, we cannot guarantee complete confidentiality.

We will share research data where we have removed anything that we think would show your identity.

There still may be a small chance that someone could figure out that the information is about you. Such sharing includes:

- Publishing results in a professional book or journal.

- Adding results to a Federal government database.

- Using research data in future studies, done by us or by other scientists.

Re-Contact

Please mark at the end of the consent form if you would like to be contacted again in the future. This contact would be after the study has ended.

\section{Subject's Rights}

By consenting to be in this study you do not waive any of your legal rights. Consenting means that you have been given information about this study and that you agree to participate in the study. You will be given a copy of this form to keep.

If you do not agree to be in this study or if at any time you withdraw from this study, you will not suffer any penalty or lose any benefits to which you are entitled. Your participation is completely up to you.

Your decision will not affect you in any way.

\section{Questions}

Copyright (C) Tiffany L. Coles, 2020 all rights reserved 
The investigator or a member of the research team will try to answer all of your questions. If you have questions or concerns at any time, contact Tiffany Coles at (951) 901-6285.

You may also call (737) 202-3343 or email eardolino@ usa.edu. You will be talking to Elizabeth Ardolino, the chairperson of the IRB at the University of St. Augustine for Health Sciences. The IRB is a group that helps monitor research. You should call or email the IRB if you want to find out about your rights as a research subject. You should also call or email if you want to talk to someone who is not part of the study about your questions, concerns, or problems.

By agreeing to be in this research, you are indicating that you have read this form (or it has been read to you), that your questions have been answered to your satisfaction, and that you

voluntarily agree to participate in this research study.

THIS PROJECT HAS BEEN REVIEWED BY THE UNIVERSITY OF ST. AUGUSTINE FOR HEALTH SCIENCES INSTITUTIONAL REVIEW BOARD FOR THE PROTECTION OF HUMAN SUBJECTS.

IF YOU HAVE QUESTIONS OR CONCERNS, PLEASE CONTACT THE INSTITUTIONAL IRB CHAIR, DR. ELIZABETH ARDOLINO, EMAIL: EARDOLINO@USA.EDU, PHONE: 737-202-3343.

$\square$ Yes, I wish to participate in this survey.

Yes, I would like to participate in a follow-up interview

- Name:

- Email:

*By providing contact information, I give my consent to participate in a follow-up interview.

No, I do not wish to participate. 


\section{Appendix D}

\section{Instructions:}

\section{Survey questions}

Please answer the following questions to the best of your ability. There are no right or wrong answers. If you do not know the answer to a question, it is acceptable to answer, "I don't know". All answers will be kept confidential.

Thank you for taking the time to complete the survey.

- Person/Performance, environment, occupation-based questions:

1. My position at the camp is:

- Director

- Counselor

- Health Staff (eg. Nurse)

- Other:

2. My Age is:

- $18-20$

- $20-25$

- $25-30$

- $30-40$

- $40+$

3. I identify as a:

- Male

- Female

- Transgender

- Non-binary

- Gender neutral

- Other:

4. I have worked at a camp for _ years.

- Short answer

5. The camp I work/worked at is considered

- Inclusive (e.g.: host's both children with and without disabilities)

- Disability-specific (e.g.: host's children with specific disabilities)

- Other:

6. My style of learning is:

- Visual

- Auditory

- Hands-on

- Other:

7. I chose to work at a camp because:

8. What is the best part of working at camp?

9. What is the most challenging part of your job here at camp?

Copyright (C) Tiffany L. Coles, 2020 all rights reserved 
10. The most popular camp song at my camp is:

11. What are typical activities found within your camp?

12. The most popular camp activity is (e.g.: archery, ropes course, horseback riding, camp songs)?

13. Have you worked with children with disabilities?

- Yes

- No

- Other:

14. Have you worked with children with hearing-impairments (e.g.: Deaf, Hard-ofHearing)?

- Yes

- No

- Other:

15. Do you speak or understand American Sign Language (ASL)?

- Yes, I am fluent in ASL

- Yes, I can speak or understand some ASL.

- No, I do not speak or understand ASL.

- Other:

16. On a scale of 1-10, How comfortable do you feel communicating with a person with hearing impairments?

- 1- Not comfortable at all, 10- Completely comfortable

17. Do you feel comfortable leading activities for children with hearing impairments?

- Yes

- No

- I have never worked with children with hearing impairments

- Other:

18. Have you ever worked with a Cochlear implant or hearing aids?

19. Do you know the proper maintenance of Cochlear implants or hearing aids?

- Yes

- No

- I have never worked with cochlear implants or hearing aids

- Other:

20. At the end of the day, who is responsible for caring for assistive devices used by the child (e.g.: glasses, contacts, hearing aids, orthotic braces, inhalers, etc)?

- The child is responsible for their devices.

- The counselor is responsible for collecting the devices and returning them each day.

- Other health professionals (e.g.: nurse/doctor on staff) collect the devices and return them each day.

- Other:

21. What types of adaptive equipment does this facility use? (Be detailed)

Copyright (C) Tiffany L. Coles, 2020 all rights reserved 
22. Do you know how to operate the adaptive equipment?

- Yes

- No

- Other:

23. What environmental barriers can you identify for a child with hearing impairments (Ex: interpreting services present, no flashing alert lights, etc)?

24. I think children with hearing impairments may have difficulty participating in types of activity?

-

25. Within the camp, I rely on my hearing to listen to children playing, thunder clouds in the distance, etc.) ? (e.g.: birds chirping,

26. How do the campers receive information (e.g.: daily schedule, camp updates, mealtimes and options, etc.)?

\section{-}

27. How do the campers know when to change activities or what is going to happen next (e.g.: PA system, campers move in groups through activities, ringing of a bell)?

28. Do the campers have free time?

- Yes

- No

- Other:

29. What is a typical day of camp like in your role?

30. How do parents of the campers influence your role?

31. On a scale of 1-10, I feel that the camp staff work well as a team.

- 1- Highly disagree, 10- Highly agree

32. On a scale of 1-10, I feel comfortable resolving conflict between two campers

- 1- Highly disagree, 10- Highly agree

33. If I do not feel comfortable settling an issue between campers, I:

34. When I see a child being excluded at camp, I:

35. What does inclusion mean to you?

36. I have the tools, education needed to promote inclusion in the camp.

37. On a scale of 1-10, I feel that my actions reflect on the campers.

- 1- highly disagree, 10-highly agree

38. On a scale of 1-10, I feel the campers model their behaviors off my actions.

- 1-highly disagree, 10- highly agree

Copyright (C) Tiffany L. Coles, 2020 all rights reserved 
39. On a scale of 1-10, I know the rights of a child with disabilities at a camp (ADA guidelines).

- 1- Do not know at all, 10- Know them well

40. On a scale of 1-10, I know how to access interpreting services.

- 1- Do not know at all, 10- Know how to access services

41. Do you know what emergency procedures are in place for children with hearing impairments at your camp?

- Yes

- No

- Other

42. What type of assistance do you think a child with hearing impairments might need?

43. What are some ways you (as a camp counselor) can encourage and support camper participation in activities (e.g.: how do you help a child if they are unable to participate in a specific activity)?

44. The campers are responsible for completing activities on their own (ex: getting dressed, cleaning up after meals, cleaning the cabin).

45. Have you received training or classes on adaptive camping or working with children with disabilities?

46. What type of training (e.g.: orientation, video, in-person training)?

Copyright (C) Tiffany L. Coles, 2020 all rights reserved 


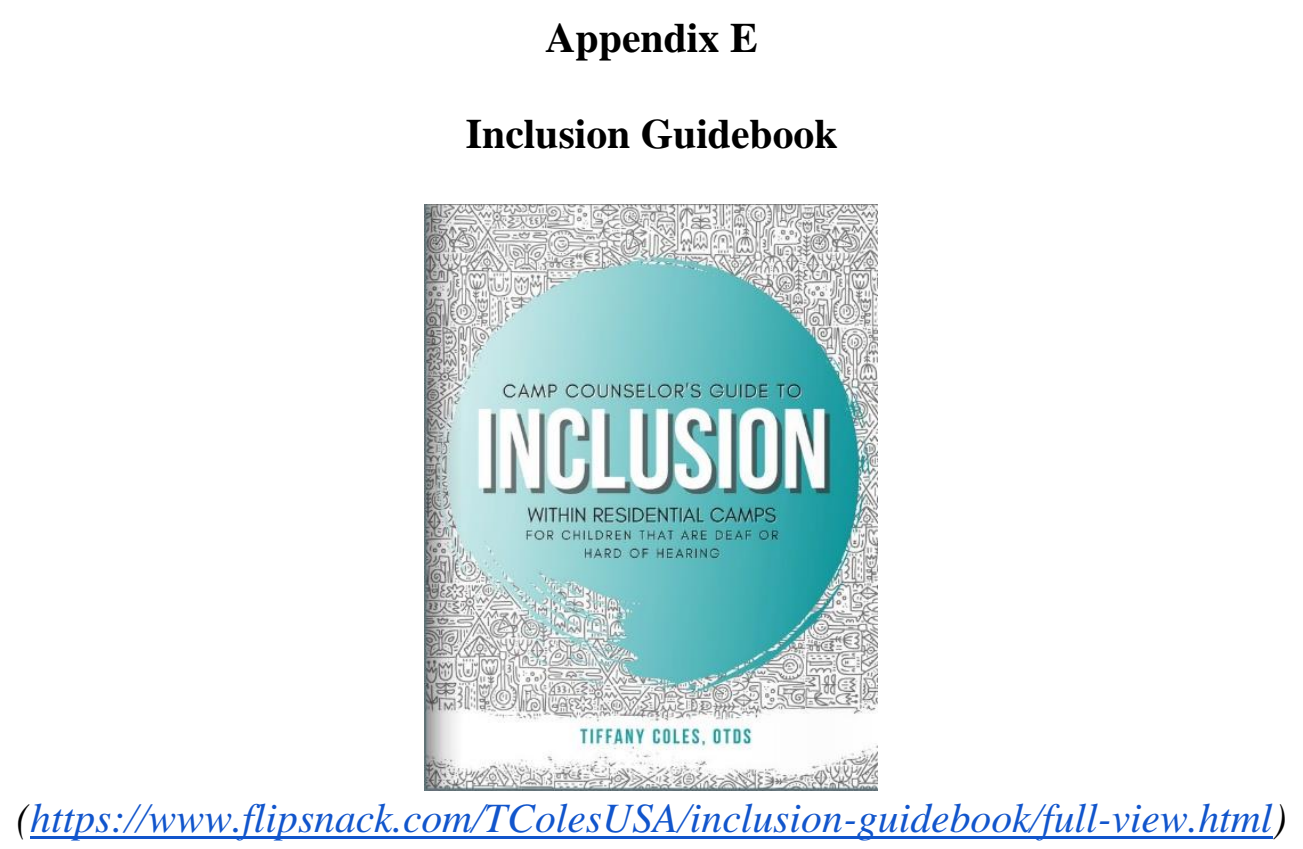

The guidebook is presented in a digital format to incorporate videos, pop-in information and links to valuable resources. This guidebook was developed under the ideas of the PEOP model. The guidebook addresses how the different factors of the camp environment (ex: accessibility provided), the occupations (ex: camp activities), and the person (the campers and camp staff) influence the performance of inclusion. By incorporating inclusionary strategies within each of these contexts, both the campers and the staff can develop inclusive mindsets and social skills that can be applied within their daily lives.

The guidebook is preceded by an about the author that details the researcher's inspiration for this project, as well as an overview of Occupational Therapy. Throughout the guidebook are tips and tricks of inclusion from the occupational therapy lens, in addition to relevant data from this research study. The guidebook is then broken down into seven chapters that range from learning the basics about hearing impairment, the camp environment, inclusion strategies, and American Sign Language education. The chapters are as follows: 


\section{Learning about Hearing Impairments}

The content in this section discusses the causes of hearing loss, functional implications of hearing impairment and statistical facts about the occurrence rate in the United States of America. General etiquette for communicating and working with deaf and hard of hearing children are discussed. Etiquette topics include proper eye-contact, visual attention grabbers, and body language. Also discussed in this section are the legal rights of deaf and hard of hearing individuals, as well as legal guidelines and acts set by the Americans with Disabilities Act, IDEA, and Section 504. Incorporated into this section is the definition of Occupational Therapy, and the meaning of the term 'occupation'.

\section{Learning about Hearing Assistive Devices}

Within this section, content includes information on how communication defines us as human beings and how it forms a foundation for decision making and relationship building (19 guidebook). Using tips provided from the National Deaf Center, we discuss effective ways to communicate with a Deaf or Hard of Hearing individual one-on-one and in large group situations. General information about the different types of assistive hearing devices, such as; amplified phones, FM systems, Hearing aid compatible phones, alerting devices, and video relay systems are provided. As well as information on how hearing aids and cochlear implants work, with problem solving solutions, and videos on proper hearing device maintenance. The occupational implications for this content suggest the counselors foster independence and confidence building by encouraging the child to learn how to advocate for themselves by developing a signal system to alert the counselor when communication is difficult. The counselor can also help the camper develop self-care skills by learning to take responsibility for the care and maintenance of their devices by gradually decreasing their assistance. 


\section{The Camp Environment}

This section begins by addressing the importance of the camp experience. As noted above, residential camps provide an ideal environment for children to experience a sense of community and belonging despite their disability. Attending residential camp is beneficial for the child's positive identity, social skills, physical skills (Bialeschki et al., 2007). This section covers the idea that children must learn to become self-reliant away from their caregivers, while engaging in new occupations, and developing strong bonds with children that may differ from their social norm. An integral part of this development is due to the role of the camp counselor. The section addresses the impact that the counselor's behaviors and mannerism have on the camper. The campers observe the counselor's interactions with other campers and staff members in a variety of settings and begin modeling their behaviors off them. The positive influence the counselor has on the child contributes to the 'Camp Counselor Cycle'.

Overall, Occupational therapists can develop programs to be restorative, socially inclusive, and therapeutic for children with disabilities. While the occupational therapist's role within the camp is relevantly new, Occupational therapists can aid in identifying and addressing physical barriers found within the camp environment and providing appropriate adaptations. Such accommodations may include providing flashing/vibrating alert systems, additional light sources, interpreting services, a camp-based communication board, and spare batteries or maintenance equipment for hearing assistive devices. A suggested packing list is provided for campers to bring items that may make their camp experience more enjoyable.

Given the current uncertainty of the global pandemic, included in this guidebook are suggestions for safely working with deaf and hard of hearing individuals during Coronavirus. 
Additionally, emergency procedure strategies for deaf and hard of hearing individuals were added to increase safety and knowledge of emergency resources available.

\section{Learning about Inclusion}

The inclusion section of this guidebook details ways that counselors can create an inclusive environment for all campers. This section describes the meaning of inclusion and how to adopt inclusive practices. These practices include strategies such as using person-first language, focusing on the child's abilities and not their disabilities, anticipating the difference the camper may need and being proactive about it, and making inclusion a group effort. While inclusion is a mindset, this section also provides physical adaptations the counselor can provide to create inclusion. These adaptations include using name tags, providing visual instructions, and offering the camper the opportunity to sit in the best position for their hearing level, while fostering their autonomy to choose what they feel comfortable with. The guidebook details that it is important to understand how to develop inclusive strategies, as well as how to identify social isolation. Within the survey, participants identified the top six camp activities campers like to participate in. Provided within the guidebook are detailed inclusive strategies for each activity, as well as visual instructions for archery, and lyrics and video links to a few camp songs.

\section{Learning ASL}

This section begins the hands-on learning portion of the guidebook. Included are charts with the American Sign Language alphabet and numbers one through twenty, basic greetings, and questions. Linked to this section is a video with 100 basic signs taught by Deaf educator Dr. Bill Vicars. 


\section{ASL Dictionary}

Within this section, there are videos of fifty common camp terms in American Sign Language. The videos can be viewed within the guidebook, with the option to go directly to the YouTube link to view more. At the end of this section are four phone applications (apps) that are useful for communicating with deaf and hard of hearing individuals. The apps include translating services, a pocket sign language dictionary, an augmentative and alternative communication board, and real time conversation translation.

\section{Additional Resources}

The final section of the guidebook provides the reader with links to further learn about the deaf and hard of hearing culture and advocacy, accommodations available, inclusive camping websites created by other University of St. Augustine students, information regarding COVID19, legal and interpreting service information, as well as link to popular camp song lyrics.

The guidebook is available to any camp counselor or instructor that would like to learn more about inclusion for deaf and hard of hearing children. 


\section{Appendix F}

\section{Poster Presentation}

\section{GT. UNIVERSITY OF ST. AUGUSTINE}

DOCTOR OF OCCUPATIONAL THERAPY PROGRAM

\section{EXPLORING ACCESSIBILITY AND SOCIAL INCLUSION FOR DEAF AND HARD OF HEARING CHILDREN IN RESIDENTIAL CAMPS THROUGH THE OCCUPATIONAL} THERAPY LENS

\section{BACKGROUND \\ Children engage in various play, leisure, and social participation activities to enhance the development of life skills, independence, and social skills (iD Tech, n.d.). Residential camps provide children a structured opportunity to engage in leisure activities while learning to become independent and self-confident when socializing and making new friends (iD Tech, n.d.). Attending camp can be a fun and engaging environment to help accelerate growth in key development outcomes, such as positive identity, social skills, physical skills, positive values, and spirituality (Bialeschki et. al., 2007). \\ PROBLEM \\ Camp counselors lack the confidence and training needed when working with Deaf and Hard of Hearing children within residential camps.}

\section{PURPOSE}

This capstone project worked to address the social and environmental needs in a residential camp to meet the physical an social needs of Deaf and Hard of Hearing

"Inclusion means that everyone gets to take part in the experience that is camp, no matter what differences they might have" -Survey Participant C

Tiffany Coles, OTDs; Susan MacDermott, OTD, OTR/L;

\section{\begin{tabular}{l} 
Surv \\
strat \\
comf \\
the \\
survey \\
culture \\
\hline \\
\hline \\
\hline
\end{tabular}}

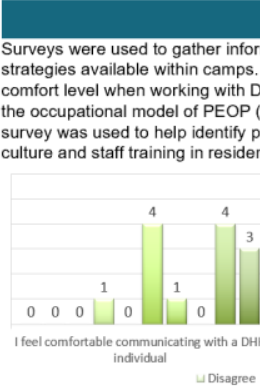
METHODS

\begin{tabular}{|c|c|}
\hline \multicolumn{2}{|c|}{ RESULTS AND THEMES } \\
\hline \multicolumn{2}{|c|}{$\begin{array}{l}\text { Results of this study found that camp staff are not comfortable or adequately trained on working with } \\
\text { Deaf and Hard of Hearing campers within the residential camp setting. Additional staff education on } \\
\text { various types of disabilities are needed to provide a truly inclusive camp experience. }\end{array}$} \\
\hline THEMES & DESCRIPTION OF THEMES \\
\hline Motivation to become a counselor & $\begin{array}{l}\text { Counselors enjoyed giving the children a chance to } \\
\text { explore the outdoors, learn new skills, and teach the } \\
\text { children about our natural environment and how to } \\
\text { be responsible for it. }\end{array}$ \\
\hline $\begin{array}{l}\text { Campers model their behaviors off the counselor's } \\
\text { actions }\end{array}$ & $\begin{array}{l}\text { Counselor sets the precedent for the next generation } \\
\text { by showing them how to serve others with inclusion } \\
\text { and respect, work hard, and develop leadership skills. }\end{array}$ \\
\hline $\begin{array}{l}\text { Accommodations are needed for Deaf and Hard of } \\
\text { Hearing campers }\end{array}$ & $\begin{array}{l}\text { Inclusive practices mean that counselors provide } \\
\text { every camper with the opportunity to play and excel } \\
\text { in every activity, while anticipating differences and } \\
\text { planning for inclusion (The Impact of a Camp } \\
\text { Counselor, 2017). }\end{array}$ \\
\hline $\begin{array}{l}\text { Counselors require additional training to work with } \\
\text { this population }\end{array}$ & $\begin{array}{l}\text { Additional staff education on various types of } \\
\text { disabilities may prove to be beneficial in providing a } \\
\text { truly inclusive camp. }\end{array}$ \\
\hline
\end{tabular}

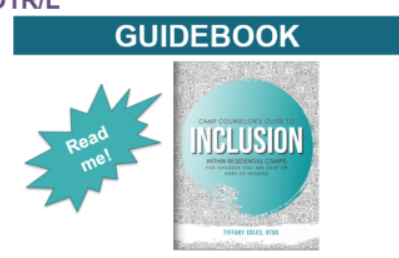

(https://Www.flipsnack.com/TColesUSA/inclusionquidebookffull-view.html)

The guidebook is presented in a digital format to incorporate videos, pop-in information and links to valuable resources. Developed under the ideas of the PEOP model, it addresses how the different factors of the camp environment (ex: accessibility provided), the occupations (ex: camp activities), and the person (the campers and camp staff) influence the performance of inclusion. By incorporating inclusionary strategies within each of these contexts, both the campers and the staff can develop inclusive mindsets and social skills that can be applied within their daily lives. Throughout the guidebook are tips and tricks of inclusion from the occupational therapy lens, in addition to relevant data from this research study. The guidebook is then broken down into seven chapters that range from learning the basics about hearing impairment, the American Sign Languase edration.

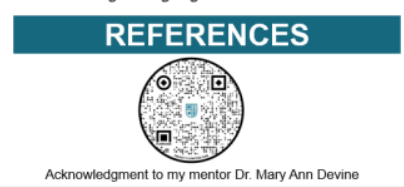

